\title{
Uma Revisão Sobre a Pesquisa Qualitativa em Ciências Sociais Aplicadas
}

\author{
A Review of Qualitative Research in the Applied Social Sciences
}

\section{Una Revisión Sobre la Investigación Cualitativa en Ciencias Sociales Aplicadas}

\author{
Maria Margarete Baccin Brizolla ${ }^{1}$ \\ marga.brizolla@gmail.com \\ http://lattes.cnpq.br/7802574351230823 \\ https://orcid.org/0000-0002-5120-0729 \\ Jonas Fernando Petry ${ }^{2}$ \\ jonaspetry@ufam.edu.br \\ http://lattes.cnpq.br/2084718061845251 \\ https://orcid.org/0000-0002-8901-1990 \\ Antônio Giovanni Figliuolo Uchôa ${ }^{2}$ \\ antoniouchoa@ufam.edu.br \\ http://lattes.cnpq.br/9770910899086151 \\ https://orcid.org/0000-0002-0451-889X \\ Herbert Luiz Braga Ferreira ${ }^{2}$ \\ herbertlbf@uol.com.br \\ http://lattes.cnpq.br/4035461749959129 \\ https://orcid.org/0000-0002-6375-9271
}

Universidade do Noroeste do Estado do Rio Grande do Sul, UNIJUI, Brasil ${ }^{1}$ Universidade Federal do Amazonas, UFAM, Brasil ${ }^{2}$

Recebido em: 26/08/2020 / Revisão: 28/08/2020 / Aprovado em: 24/09/2020

Editores responsáveis: Prof. Dr. Antônio Giovanni Figliuolo Uchôa e Prof. Dr. Jonas Fernando Petry

Processo de Avaliação: Double Blind Review

DOI: https://10.47357/ufambr.v2i3.8087 


\title{
Resumo
}

Este artigo apresenta uma revisão da literatura sobre a pesquisa qualitativa no campo das ciências sociais aplicadas, em especial na administração de empresas, demonstrando como a abordagem qualitativa e suas diferentes formas de emprego podem contribuir para o entendimento de um fenômeno. Os debates sobre métodos de pesquisa nas ciências sociais estão diretamente ligados a suposições sobre a ontologia, a epistemologia e a natureza humana (Morgan \& Smircich, 1980). A revisão fornece uma introdução às diferentes abordagens qualitativas, seus pressupostos teóricos fundamentais, suas origens históricas e seus procedimentos investigativos. A pesquisa qualitativa, em sua essência, consiste na arte de transmitir e interpretar significados, baseando-se na coleta de dados de natureza qualitativa e numa teorização de caráter sobretudo indutivo. Os dados qualitativos podem ser textos não redutíveis, incluindo palavras e recursos visuais apresentados de forma estática ou dinâmica. Embora esses dados qualitativos possam ser digitalizados, sintetizados e até contados, fazê-lo requer interpretação dos dados para discernir padrões e insights. Dadas as formas amplas em que os dados qualitativos podem aparecer, as premissas epistemológicas de um pesquisador geralmente moldam suas abordagens a esse processo analítico. A pesquisa qualitativa apresenta novas percepções que geralmente podem introduzir a teoria em direções completamente novas (Bansal, Smith, \& Vaara, 2018). É fundamental que os pesquisadores qualitativos ofereçam relatos detalhados de suas fontes e análises de dados. Um detalhamento minucioso é necessário desde o início do projeto até o envio do manuscrito, dando sentido ao relato dos dados e da teoria emergente, além de sinalizar a qualidade do exercício de pesquisa, a credibilidade do pesquisador e, finalmente, a confiabilidade dos dados e a teorização emergente. Como tal, o pesquisador geralmente apresenta com destaque, em primeira pessoa e reflexivamente, a descrição dos métodos (Bansal \& Corley, 2017). Ao descrever as possíveis aplicações da abordagem qualitativa, o objetivo desta revisão é apoiar futuros pesquisadores das ciências sociais aplicadas que se valem das observações dos dados para introduzir conhecimentos abstratos que podem ser generalizados além dos contextos específicos. A teorização indutiva baseada em dados pode ampliar o quadro epistemológico dos pesquisadores com saltos mais longos do que a lógica hipodedutiva baseada em dados quantitativos, produzindo assim ideias completamente novas (Bansal, Smith, \& Vaara, 2018). Por fim, os métodos qualitativos são variados e podem fornecer grandes contribuições, aproximando novos pesquisadores e inspirando novas pesquisas, ampliando a forma de ver as ciências sociais aplicadas.

Palavras chave: Pesquisa qualitativa; pesquisa em ciências sociais aplicadas; Revisão sobre pesquisa qualitativa.

\section{A Review of Qualitative Research in the Applied Social Sciences}

\begin{abstract}
This article presents a review of literature on qualitative research in the field of the applied social sciences, in particular in management studies, showing how qualitative approaches and their different forms of application can contribute to understanding of a phenomenon. Debates about research methods in the social sciences are directly related to assumptions about ontology, epistemology, and human nature (Morgan \& Smircich, 1980). This review serves as an introduction to the different approaches, to the assumptions underlying research, to its historical origins, and to its procedures. The essence of qualitative research encompasses the art of transmitting and interpreting meaning, primarily based on qualitative data and inductive theorizing. Qualitative data could be non-reducible texts, including words and visual resources, delivered in static or dynamic form. Although these qualitative data can be digitized,
\end{abstract}


synthesized, and even counted, to do so it is necessary to interpret the data to discern patterns and yield insights. Given the wide range of forms in which qualitative data can appear, researchers' epistemological premises generally mold their approaches to this analytical process. Qualitative research presents new perceptions that in general can induce theory in completely new directions (Bansal, Smith, \& Vaara, 2018). It is essential that qualitative researchers provide detailed reports on their data sources and analyses. An extremely detailed description of all aspects from the initial research design through to submission of the manuscript adds meaning to the data reports and emerging theory, in addition to indicating the quality of the research exercise, the credibility of the researcher and, finally, the reliability of the data and the emerging theory under construction. Therefore, researchers generally put emphasis on a first-person and reflexive description of their methods (Bansal \& Corley, 2017). The objective of this review in describing the possible applications of the qualitative approach is to support future researchers in the applied social sciences to employ observation of data to introduce abstract knowledge that can be generalized beyond their specific contexts. Inductive theorizing based on data can expand researchers' epistemological bases, taking longer strides than with hypodeductive logic based on quantitative data, thereby producing completely new ideas (Bansal, Smith, \& Vaara, 2018). Finally, qualitative methods are varied and can make major contributions, attracting new researchers and inspiring new research, amplifying their image of the applied social sciences.

Keywords: Qualitative research; applied social sciences research; Review of qualitative research.

\section{Una Revisión Sobre la Investigación Cualitativa en Ciencias Sociales Aplicadas}

\section{Resumen}

Este artículo presenta una revisión de la literatura producida sobre la investigación cualitativa en el campo de las ciencias sociales aplicadas, especialmente en la administración de empresas, demostrando cómo el enfoque cualitativo y sus diferentes formas de empleo pueden contribuir al entendimiento de un fenómeno. Los debates sobre métodos de investigación en las ciencias sociales están directamente vinculados a suposiciones sobre la ontología, la epistemología y la naturaleza humana (Morgan \& Smircich, 1980). La revisión proporciona una introducción a los diferentes enfoques, a las suposiciones básicas de investigación, a los orígenes históricos y a los procedimientos. La investigación cualitativa en su esencia abarca el arte de transmitir e interpretar significado, se basa principalmente en datos cualitativos y teorización inductiva. Los datos cualitativos pueden ser textos no reducibles, incluyendo palabras y recursos visuales entregados en forma estática o dinámica. Aunque estos datos cualitativos pueden ser digitalizados, sintetizados e incluso contados, hacerlo primero requiere una interpretación de los datos para discernir patrones e insights. Dadas las formas amplias en las que los datos cualitativos pueden aparecer, las premisas sobre las epistemologías de un investigador, generalmente, moldean sus enfoques a ese proceso analítico. La investigación cualitativa presenta nuevas percepciones que, comúnmente, pueden introducir la teoría en direcciones completamente nuevas (Bansal, Smith, \& Vaara, 2018). Es fundamental que los investigadores cualitativos ofrezcan relatos detallados de sus fuentes y análisis de datos. Un nivel de detalle minucioso, desde el inicio del proyecto hasta el envío del manuscrito, dará sentido a los relatos de datos y a la teoría emergente, además de señalar la calidad del ejercicio de investigación, la credibilidad del investigador y, finalmente, la fiabilidad de los datos y de la teorización emergente. Como tal, lo primero que, generalmente, el investigador destaca, en primera persona y reflexivamente, es la descripción de los métodos (Bansal \& Corley, 2017). Al describir las 
posibles aplicaciones del enfoque cualitativo, el objetivo de esta revisión es apoyar a futuros investigadores de las ciencias sociales aplicadas que se valen de las observaciones de datos para introducir conocimientos abstractos, que pueden generalizar más allá de los contextos específicos. La teorización inductiva basada en datos puede ampliar el cuadro epistemológico de los investigadores con saltos más largos que la lógica hipodeductiva basada en datos cuantitativos, produciendo así ideas completamente nuevas (Bansal, Smith, \& Vaara, 2018). Por último, los métodos cualitativos son variados y pueden aportar grandes contribuciones, acercando a nuevos investigadores e inspirando nuevas investigaciones que amplíen la forma de ver las ciencias sociales aplicadas.

Palabras clave: Investigación cualitativa; investigación en ciencias sociales aplicadas; Revisión sobre investigación cualitativa. 


\section{INTRODUÇÃo}

Esta revisão apresenta as questões relacionadas à pesquisa qualitativa, buscando proporcionar elementos que extrapolem a questão da técnica e do método na busca da compreensão de um fenômeno. O estudo da pesquisa qualitativa vem se ampliando nos últimos anos, com a publicação de estudos que adotam métodos de investigação de natureza qualitativa, bem como de manuais dedicados exclusivamente à pesquisa qualitativa, procurando orientar pesquisadores e estudantes no uso de procedimentos qualitativos na coleta, análise e apresentação dos dados da pesquisa (Silverman, 2017). Assim, a pesquisa qualitativa refere-se a um recorte de pesquisa em geral cujo foco não pretende tomar conotação de defesa ou prioridade, ou ainda de segmentação, mas sim de aprofundamento, caracterização e compreensão sobre o tema (Silva \& Emmendoerfer, 2014).

O mundo dos negócios pode ser analisado e compreendido utilizando-se métodos qualitativos; no entanto, existe nesse mundo um preconceito contra a pesquisa qualitativa, visto que a tradição colocou a pesquisa quantitativa como sendo a abordagem científica por excelência, relegando a pesquisa qualitativa a um status inferior, podendo servir apenas como um levantamento prévio de dados que seriam abordados posteriormente de forma quantitativa. As pesquisas em ciências sociais têm mostrado outras formas de pesquisa através do desenvolvimento de ferramentas qualitativas para complementar e, quando apropriado, para transcender a análise científica quantitativa ao combinar a orientação qualitativa com técnicas paralelas que derivam de outras disciplinas, daí resultando uma poderosa sinergia. E, em muitas ocasiões, é essa sinergia que fornece aos analistas os conhecimentos necessários para entender a situação (Walle, 2015).

O século XVII testemunhou uma verdadeira revolução na mentalidade europeia. É nesse século que a Europa assiste o que mais tarde vai ser chamado de "revolução científica" (Hall, 1983), que a consciência europeia entra em crise (Hazard, 1994) e que as ciências positivas começam a distinguir-se e separar-se da Filosofia, especialmente a Astronomia e a Física, iniciando a revolução que conduzirá do mundo fechado e finito da cosmologia greco-romana e medieval ao universo infinito de Galileu e Kepler (Koyré, 1973). Nesse novo mundo, o experimento, a dimensão empírica são doravante essenciais, porque não se compreenderá mais o que é fazer ciência sem que se aborde essa dimensão (Bertero, 2013).

A revolução científica do século XVII começou com as ciências da Natureza, acarretando, sobretudo, a matematização da Natureza, isto é, a utilização das ciências matemáticas como instrumento fundamental para a análise, descrição e, em última instância, a explicação dos fenômenos da Natureza. Os avanços espetaculares da Física, da Astronomia, da Química consolidaram a tradição da pesquisa quantitativa, voltada para a mensuração e a quantificação, apoiadas pelas ciências matemática na investigação dos fenômenos do mundo natural. As Ciências do Homem, incluindo-se entre elas as Ciências Sociais, foram os últimos galhos a desprender-se do tronco antigo e venerável da Filosofia, assumindo assim, elas também, a vontade de constituírem-se como ciências positivas. Chegadas mais recentemente na crescente divisão e especialização do conhecimento, as Ciências do Homem, na sua luta pela admissão e legitimação científica e acadêmica, tentaram frequentemente emular os procedimentos das ciências da Natureza, adotando a visão positivista, empírica e matematizante das ciências da Natureza e os métodos de investigação quantitativos, sobretudo o método experimental como $o$ paradigma de toda investigação que se pretenda verdadeiramente científica. Com essa orientação decididamente quantitativa, a pesquisa qualitativa demorou a impor-se como uma alternativa válida tanto em termos epistemológicos quanto metodológicos no leque de opções 
para o desenho de uma investigação científica, o que se constata quando se olha para a longa e atribulada história dos métodos qualitativos nas ciências humanas.

Na sociologia, o trabalho realizado pela escola de Chicago nas décadas de 1920 e 1930 determinou a importância da investigação qualitativa para o estudo das sociedades, comunidades e grupos humanos. Na mesma época, na antropologia, os estudos de Boas, Mead, Benedict, Bateson, Evans-Pritchard, Radcliffe-Brown e Malinowski, definiram a disciplina e traçaram os contornos do método de trabalho de campo. $\mathrm{O}$ antropólogo partia para lugares distantes, usualmente fora do mundo ocidental urbano e industrializado, para observar comunidades ágrafas, radicalmente diferentes do mundo europeu ocidental, a fim de estudar os costumes e os hábitos de outras sociedade e culturas, as quais foram durante muito tempo chamadas de 'primitivas' (Denzin \& Lincoln, 2006). As ciências sociais, como dissemos há pouco, foram os últimos rebentos de um longo processo iniciado já no Renascimento e que se estenderá até o final do século XIX e os primeiros anos do século XX, com os pais fundadores da sociologia, Auguste Comte, Émile Durkheim, Max Weber; com o estabelecimento da Psicologia experimental com os trabalhos de Wilhelm Wundt e Wiliam James e, num tom profético e visionário, com o estabelecimento da Economia Política, com Marx (Bertero, 2013).

A pesquisa qualitativa tornou-se mais visível durante a década de 1990 e no século 21. Alguns livros resumiram os vários tipos de pesquisa qualitativa, como as 19 estratégias identificadas por Wolcott (2001), e seus procedimentos estão disponíveis em abordagens específicas na investigação qualitativa. Por exemplo, Clandinin e Connelly (2000)construíram uma imagem de que os pesquisadores narrativos fazem. Moustakas (1994) discutiu os princípios filosóficos e os procedimentos do método fenomenológico, e Corbin e Strauss (1990; 1998), identificaram os procedimentos da teoria fundamentada. Wolcott (1999) resumiu os procedimentos etnográficos, e Stake (1995) debateu os processos envolvidos no estudo de caso.

A pesquisa qualitativa envolve o uso de uma variedade de materiais empíricos como, por exemplo, o estudo de caso, experiência pessoal, introspecção, história de vida, entrevistas, artefatos, textos e produções culturais, textos observacionais, históricos, interativos e visuais, que descrevem momentos e significados rotineiros e/ou problemáticos na vida dos indivíduos (Denzin \& Lincoln, 2006). A literatura sobre a diversidade de métodos e abordagens qualitativos é copiosa, podendo-se citar, entre outros, a pesquisa-ação participativa (Atweh, Kemmis, \& Weeks, 1998), a análise do discurso (Cheek, 2004), etnografia (Creswell, 2007), teoria fundamentada em dados (Corbin \& Strauss, 1990; 1998; Charmaz, 2006), estudo de caso (Stake, 1995), pesquisa fenomenológica (Moustakas, 1994), investigação narrativa (Clandinin \& Connelly, 2000).

A pesquisa qualitativa é, em si mesma, um campo de investigação que atravessa disciplinas, campos e temas (Denzin \& Lincoln, 2006). Em torno do tema há uma complexa interligação de definições e suposições, entre elas as tradições associadas ao fundacionalismo, ao positivismo, ao pós-fundacionalismo, ao pós-positivismo, ao pós-estruturalismo e aos diversos métodos de pesquisa qualitativa relacionados aos estudos culturais (Denzin \& Lincoln, 2006).

A pesquisa qualitativa é um meio para conhecer, compreender e explicar os significados que indivíduos e/ou grupos atribuem aos fenômenos de ordem social e/ou psíquica nos quais esses indivíduos e grupos estão inseridos. Os procedimentos de pesquisa na pesquisa qualitativa não utilizam métodos de coleta e análise de dados tais como os métodos experimental e quaseexperimental que, obrigatoriamente, envolvem procedimentos numéricos e estatísticos, já que 
o que se deseja é mensurar, medir, quantificar. Na pesquisa qualitativa, as questões que o pesquisador se coloca dizem respeito não ao "quanto", mas ao "como". A análise de dados que leva à construção de elementos para temas gerais; as interpretações sobre o significado desses dados competem ao pesquisador. O relatório final tem uma estrutura flexível. Aqueles que se dedicam a essa forma de investigação apoiam uma forma de olhar para a pesquisa que privilegia um estilo indutivo, um foco no sentido individual, bem como a avaliação da complexidade de uma situação (Creswell, 2007).

Muitas vezes, a distinção entre pesquisa qualitativa e quantitativa é enquadrada em termos verbais (qualitativa) em vez de números (quantitativa), ou usar perguntas fechadas (hipóteses quantitativas) ao invés de perguntas abertas (perguntas da entrevista qualitativa). A maneira mais completa para ver as gradações de diferenças entre eles está nos pressupostos filosóficos básicos que os pesquisadores trazem para o estudo, os tipos de estratégias de pesquisa utilizadas no geral da pesquisa (por exemplo, experimentos quantitativos ou estudos de caso qualitativos) e os métodos específicos empregados na realização dessas estratégias (por exemplo, a coleta de dados quantitativos sobre os instrumentos de coleta de dados qualitativos em relação à observação de um ajuste). Além disso, há uma evolução histórica para ambas as abordagens, com as abordagens quantitativas dominando as formas de pesquisa nas ciências sociais a partir do final do século 19 até meados do século 20. Durante a segunda metade do século 20, o interesse pela pesquisa qualitativa aumentou e junto com ela, o desenvolvimento de métodos mistos de investigação (Creswell, 2008; 2013).

A pesquisa qualitativa pode ser definida como uma atividade situada que localiza o observador no mundo. Consiste em um conjunto de práticas materiais e interpretativas que dão visibilidade ao mundo. Essas práticas transformam o mundo em uma série de representações, incluindo as notas de campo, as entrevistas, as conversas, as fotografias, as gravações e os lembretes (Creswell, 2007).

Como já mencionado, a pesquisa qualitativa envolve o estudo do uso e coleta de uma variedade de materiais empíricos (exemplo: estudo de caso, experiência pessoal, introspecção, história de vida, entrevista, artefatos, textos e produções culturais, textos observacionais, históricos, interativos e visuais) que descrevem momentos e significados rotineiros e problemáticos na vida dos indivíduos (Denzin \& Lincoln, 2006).

A pesquisa qualitativa abrange uma ampla variedade de abordagens, mas, por definição, nenhuma dessas abordagens baseia-se em medições numéricas (King, Keohane, \& Verba, 1994). Os pesquisadores utilizam uma ampla variedade de práticas interpretativas interligadas na esperança de sempre conseguirem compreender melhor o assunto que está ao seu alcance (Denzin \& Lincoln, 2006).

A ciência social constitui uma tentativa de dar sentido a situações sociais que percebemos como mais ou menos complexas. Os métodos científicos podem ser tão valiosos para eventos intrinsecamente complexos como para os mais simples. Não podemos construir explicações causais significativas sem uma boa descrição, descrição que, por sua vez, perde a maior parte de seu interesse quando esteja associada a algumas relações causais. Descrição muitas vezes vem em primeiro lugar. É difícil desenvolver explicações antes de sabermos algo sobre o mundo e o que precisa ser explicado com base em quais características. Mas a relação entre descrição e explicação é interativa. Às vezes nossas explicações nos levam a olhar para descrições de diferentes partes do mundo, por outro lado, nossas descrições podem levar a novas explicações causais. Descrição e explicação ambas dependem de regras de inferência científica (Shanteau, 
1972; King, Keohane, \& Verba, 1994; Hug, 2013). Entende-se, contudo, que cada prática garante uma visibilidade diferente do mundo. Logo, geralmente, existe um compromisso no sentido do emprego de mais de uma prática interpretativa em qualquer estudo (Denzin \& Lincoln, 2006).

A utilização da metodologia qualitativa está alicerçada no pressuposto de que há diversos tipos de saber e de ciência, da mesma maneira que o conhecimento científico não é a única forma de conhecimento. A ciência pode assumir várias formas, uma questão clássica em epistemologia é a acumulação de conhecimento (Bertero, 2013). Foi uma das fontes que levaram ao clássico ensaio de Thomas Kuhn (Kuhn, 1996) e cuja resposta veio pelo desenvolvimento do conceito, hoje amplamente difundido, de paradigma (Bertero, 2013).

Por fim, as posições qualitativas baseiam-se especialmente na fenomenologia e no marxismo. A fenomenologia é o estudo ou a ciência do fenômeno (Sanders, 1982; Kockelmans, 1994). A pesquisa qualitativa com base no marxismo traz novos problemas de estudo sobre culturas diferente, grupos e subgrupos, e introduz novos aportes teóricos e metodológicos sobre a significação na pesquisa do sujeito nas suas interações, com outros e com a sociedade (Chizzotti, 2003). O marxismo é baseado em uma preocupação com a atividade prática associada à natureza humana e às necessidades humanas básicas (Oilman, 1976). Essas necessidades são previstas por sistemas econômicos, a análise dinâmica do capitalismo explica a produção e a distribuição de mercadorias (Thorpe \& Holt, 2007).

\section{METODOLOGIA QUALITATIVA}

O paradigma da investigação qualitativa tem suas raízes na antropologia cultural e na sociologia americana (Kirk \& Miller, 1986). Só recentemente foi adotada por pesquisadores sociais e educacionais (Gall, Borg, \& Gall, 2003). A intenção da pesquisa qualitativa é entender uma determinada situação social, evento, papel, grupo ou interação (Locke, Spirduso, \& Silverman, 2013).

É em grande parte um processo de investigação em que o investigador gradualmente faz sentido de um fenômeno social, contrastando, comparando, replicando, catalogando e classificando o objeto de estudo (Miles, Huberman, \& Saldaña, 2013). Marshall e Rossman (2006) sugerem que a pesquisa qualitativa implica imersão da vida cotidiana da definição escolhida para o estudo, o pesquisador entra no mundo e através da interação em curso, procura os informantes, as perspectivas e os significados (Creswell, 2013).

O campo de pesquisa qualitativa é marcado por uma série de tensões, contradições e hesitações. Trata-se de um campo em constante movimento, cujos arcabouços epistemológicos e orientações metodológicas têm sido continuamente examinados e questionados à medida que se defrontam com um mundo histórico inconstante, com novas posturas intelectuais e com condições institucionais e acadêmicas (Godoy A. S., 2013).

A trajetória histórica da pesquisa qualitativa parte da escola norte-americana e revela um alinhamento com as tradições pragmáticas, naturalistas e interpretativas (Godoy A. S., 2013). A pesquisa qualitativa cultiva a mais útil de todas as capacidades humanas: a capacidade de aprender (Patton, 2002). A pesquisa qualitativa agrupa uma complexa e interconectada família de termos, conceitos, pressupostos e tradições (Denzin \& Lincoln, 2005), que tem sua origem nos 50 anos iniciais do século 20, a partir da Escola de Chicago e dos trabalhos de campo desenvolvidos no âmbito da antropologia (Godoy A. S., 2013). 
A pesquisa qualitativa é uma atividade situada que localiza o observador no mundo. Trata-se de um conjunto de práticas interpretativas que tornam o mundo visível. Essas práticas transformam o mundo. A pesquisa qualitativa transforma o mundo em uma série de representações, incluindo notas de campo, entrevistas, conversas, fotografias, gravações e memorandos etc. A este nível, a pesquisa qualitativa envolve uma abordagem interpretativa, naturalista ao assunto em questão. Isso significa que os pesquisadores qualitativos estudam as coisas em seus ambientes naturais, tentando dar sentido ou interpretar fenômenos em termos dos significados que as pessoas trazem para eles.

A pesquisa qualitativa envolve o uso estudado e a coleção de uma variedade de materiais empíricos - estudo de caso, a experiência pessoal, introspecção, história de vida, entrevista, artefatos, textos e produções culturais, textos históricos, interacionais e visuais - que descrevem momentos rotineiros e problemáticos e significativos na vida dos indivíduos. Assim, os pesquisadores qualitativos implantam uma ampla gama de métodos interligados, esperando sempre para obter uma solução melhor para o assunto em mãos (Hughes, 2003).

Pesquisadores que abraçam as metodologias qualitativas dão ênfase à ideia de que a realidade é socialmente construída, admitem que existe um íntimo relacionamento entre pesquisador e seu objeto de estudo, assumem o caráter situacional presente em qualquer investigação (Godoy A. S., 2013).

\subsection{Métodos específicos das ciências sociais}

Método apresenta uma considerável variedade de significados, no entanto, em um sentido amplo, método "é o processo ou o conjunto de processos que permite conhecer determinada realidade, produz certo objeto, ou desempenhar este ou aquele tipo de comportamento" (Hegenberg, 2012, p. 9). O método nada mais é do que o procedimento, o processo, a técnica, ou o modo de investigar para descobrir os dados passíveis de experimentação e controle (Hegenberg, 2012).

O método científico oferece ao pesquisador um exemplo básico de como conduzir os experimentos para garantir que as experiências atinjam determinados padrões de qualidade e que as conclusões das experiências sejam credíveis. Compreender os princípios essenciais do método científico pode ajudar a usar o método eficiente e eficaz. O método científico é um conjunto de técnicas para a investigação de fenômenos, a aquisição de novos conhecimentos, ou para corrigir e integrar conhecimentos prévios (Bauer, 1994).

Para ser chamado de científico, um método de investigação deve basear-se no empirismo e ser possível de mensuração (Morgan \& Smircich, 1980; Assis, 1993; Johnson \& Onwuegbuzie, 2004; May, 2011; Vaus, 2014). O método científico é definido como um método ou procedimento que tem caracterizado as ciências naturais desde o século 17, e que consiste na observação sistemática, na medição e na experiência, bem como na formulação de testes e na modificação de hipóteses (Morgan \& Smircich, 1980).

Entre os vários conceitos de métodos, algumas definições são apresentadas no Tabela 1:

Tabela 1

Conceitos de métodos

\begin{tabular}{l|l} 
CONCEITOS & REFERENCIA
\end{tabular}




\begin{tabular}{|c|c|}
\hline $\begin{array}{l}\text { Método é o caminho pelo qual se chega a determinado resultado, ainda que } \\
\text { esse caminho não tenha sido fixado de antemão de modo refletido e deliberado. }\end{array}$ & (Hegenberg, 1976:II-115). \\
\hline $\begin{array}{l}\text { Método é uma forma de selecionar técnicas, forma de avaliar alternativas para } \\
\text { ação científica... Assim, enquanto as técnicas utilizadas por cientista são fruto } \\
\text { de suas decisões, o modo pelo qual tais decisões são tomadas depende de suas } \\
\text { regras de decisão. Métodos são regras de escolha; técnicas são as próprias } \\
\text { escolhas. }\end{array}$ & $\begin{array}{l}\text { (Ackof In Hegenberg, 1976: } \\
\text { II-116). }\end{array}$ \\
\hline $\begin{array}{l}\text { Método é a forma de proceder ao longo caminho. Na ciência os métodos } \\
\text { constituem os instrumentos básicos que ordenam de início o pensamento em } \\
\text { sistemas, traçam de modo ordenado a forma de proceder do cientista ao longo } \\
\text { de um percurso para alcançar um objetivo. }\end{array}$ & (Trujillo, 1974:24). \\
\hline $\begin{array}{l}\text { Método é a ordem que se deve impor aos diferentes processos necessários para } \\
\text { atingir um fim dado (...) é o caminho a seguir para chegar à verdade nas } \\
\text { ciências. }\end{array}$ & (Jolivet, 1979:710. \\
\hline $\begin{array}{l}\text { Em um sentido mais geral, o método é a ordem que se deve impor aos } \\
\text { diferentes processos necessários para atingir um fim dado ou um resultado } \\
\text { desejado. Nas ciências, entende-se por método o conjunto de processos que o } \\
\text { espírito humano deve empregar na investigação e demonstração da verdade. }\end{array}$ & (Cervo\& Bervian, 1978:17). \\
\hline $\begin{array}{l}\text { Método é o conjunto coerente de procedimentos racionais ou práticos-racionais } \\
\text { que orienta o pensamento para serem alcançados conhecimentos válidos. }\end{array}$ & (Nérici, 1978:15). \\
\hline $\begin{array}{l}\text { Método é um procedimento regular, explícito e passível de ser repetido para } \\
\text { conseguir-se alguma coisa, seja material ou conceitual. }\end{array}$ & (Bunge, 1980:19). \\
\hline $\begin{array}{l}\text { Método científico é um conjunto de procedimentos por intermédio dos quais } \\
\text { (a) se propõe os problemas científicos e (b) colocam-se à prova as hipóteses } \\
\text { científicas. }\end{array}$ & (Bunge, 1974 \\
\hline $\begin{array}{l}\text { A característica distintiva do método é a de ajudar a compreender, no sentido } \\
\text { mais amplo, não os resultados da investigação científica, mas o próprio } \\
\text { processo de investigação. }\end{array}$ & $\begin{array}{l}\text { (Kaplan In: Grawitz, 1975:I- } \\
\text { 18). }\end{array}$ \\
\hline
\end{tabular}

Fonte: Adaptado Lakatos e Marconi(2011, pp. 44-45).

O fim a que se destina a atividade científica é a aproximação gradativa e cumulativa da verdade, por intermédio da comprovação de hipóteses, que por sua vez, são pontes entre a observação da realidade e a teoria científica, que explicam a realidade. O método é o conjunto das atividades sistemáticas e racionais que permite alcançar o objetivo, traçando o caminho a ser seguido (Lakatos \& Marconi, 2011).

A prática científica é parte de um acontecer onde o pesquisador e o sujeito de pesquisa encontram-se situados em práticas concretas onde compartilham significados historicamente construídos (Bulgacov, 2013). O método se caracteriza por uma abordagem mais ampla na abstração dos fenômenos da natureza e da sociedade, para isso, é preciso um método de abordagem evidenciado na Tabela 2 a seguir:

Tabela 2

Métodos de procedimento de investigação

\begin{tabular}{|c|l|l|}
\hline MÉTODO & \multicolumn{1}{|c|}{ DESCRIÇÃO } & \multicolumn{1}{|c|}{ REFERÊECIA } \\
\hline Método indutivo & $\begin{array}{l}\text { Cuja aproximação dos fenômenos caminha geralmente para } \\
\text { planos cada vez mais abrangentes, indo das constatações mais } \\
\text { particulares às leis e teorias (conexão ascendente). }\end{array}$ & $\begin{array}{l}\text { (Lakatos \& Marconi, } \\
2011, \text { p. 90). }\end{array}$ \\
\hline $\begin{array}{c}\text { Método } \\
\text { dedutivo }\end{array}$ & $\begin{array}{l}\text { Que, partindo das teorias e leis, na maioria das vezes prediz a } \\
\text { ocorrência dos fenômenos particulares (conexão descendente). }\end{array}$ & $\begin{array}{l}\text { (Lakatos \& Marconi, } \\
\text { 2011, p. 91). }\end{array}$ \\
\hline $\begin{array}{c}\text { Método } \\
\text { hipotético- } \\
\text { dedutivo }\end{array}$ & $\begin{array}{l}\text { Que se inicia pela percepção de uma lacuna nos conhecimentos, } \\
\text { acerca da qual formula hipóteses e, pelo processo de inferência } \\
\text { dedutiva, testa a predição da ocorrência de fenômenos pela } \\
\text { hipótese. }\end{array}$ & 2011, p. 91). \\
\hline Método dialético & $\begin{array}{l}\text { Que penetra o mundo dos fenômenos tendo em vista a ação } \\
\text { recíproca da contradição inerente ao fenômeno e da mudança } \\
\text { dialética que ocorre na natureza e na sociedade. }\end{array}$ & 2011, p. 91). \\
\hline
\end{tabular}




\begin{tabular}{|c|c|c|}
\hline $\begin{array}{l}\text { Método } \\
\text { histórico }\end{array}$ & $\begin{array}{l}\text { Consiste em localizar, avaliar e sintetizar sistemática e } \\
\text { objetivamente as provas, para estabelecer os fatos e obter } \\
\text { conclusões referentes aos acontecimentos do passado. }\end{array}$ & (Borg, 1974, p. 81). \\
\hline $\begin{array}{c}\text { Método } \\
\text { comparativo }\end{array}$ & $\begin{array}{l}\text { Empregado por Tylor. Procede pela investigação de indivíduos, } \\
\text { classes, fenômenos ou fatos, com vistas a ressaltar as diferenças e } \\
\text { similaridades entre eles. }\end{array}$ & (Gil, 2012, p. 16). \\
\hline $\begin{array}{c}\text { Método } \\
\text { monográfico }\end{array}$ & $\begin{array}{l}\text { Criado por Le Play, parte do princípio de que o estudo de um caso } \\
\text { em profundidade pode ser considerado representativo de muitos } \\
\text { outros ou mesmo de todos os casos semelhantes. Esses casos } \\
\text { podem ser indivíduos, instituições, grupos, comunidades etc. }\end{array}$ & (Gil, 2012, p. 16). \\
\hline $\begin{array}{l}\text { Método } \\
\text { estatístico }\end{array}$ & $\begin{array}{l}\text { Fundamenta-se na aplicação da teoria estatística da probabilidade. } \\
\text { A estatística é uma parte da matemática aplicada que fornece } \\
\text { métodos para coleta, organização, descrição, análise e } \\
\text { interpretação de dados e para a utilização dos mesmos na tomada } \\
\text { de decisões. }\end{array}$ & $\begin{array}{l}\text { (Richardson, 2010, p. } \\
\text { 70; Gil, 2012, p. 17). }\end{array}$ \\
\hline $\begin{array}{l}\text { Método } \\
\text { tipológico }\end{array}$ & $\begin{array}{l}\text { Habitualmente empregado por Max Weber. Apresenta certas } \\
\text { semelhanças com o método comparativo. Comparando fenômenos } \\
\text { sociais complexos, o pesquisador cria tipos ou modelos ideais. A } \\
\text { característica principal do tipo ideal é não existir na realidade, mas } \\
\text { servir de modelo para análise e compreensão de casos concretos. }\end{array}$ & (Gil, 2012, p. 17). \\
\hline $\begin{array}{c}\text { Método } \\
\text { estruturalista }\end{array}$ & $\begin{array}{l}\text { É um método de investigação, aplicando-se a teoria linguística } \\
\text { para uma grande variedade de objetos e atividades, fortemente } \\
\text { influenciada pela antropologia cultural, especialmente a de Claude } \\
\text { Lévi-Strauss, que estudou os mitos, sistemas de parentesco, } \\
\text { rituais, etc. } \\
\text { O estruturalismo parte do pressuposto de que cada sistema é um } \\
\text { jogo de oposições, presenças e ausências, constituindo uma } \\
\text { estrutura, onde o todo e as partes são interdependentes, de tal } \\
\text { forma que as modificações que ocorrem num dos elementos } \\
\text { constituintes implica modificação de cada um dos outros e do } \\
\text { próprio conjunto. }\end{array}$ & $\begin{array}{l}\text { (Smithson, 1975; } \\
\text { Gil, 2012, p. 19). }\end{array}$ \\
\hline $\begin{array}{c}\text { Método } \\
\text { funcionalista }\end{array}$ & $\begin{array}{l}\text { O funcionalismo é uma corrente das ciências humanas que enfatiza } \\
\text { as relações e o ajustamento entre os diversos componentes de uma } \\
\text { cultura ou sociedade. Suas origens prendem-se aos positivistas } \\
\text { Herbert Spencer (1820-1903) e Émile Durkheim (1858-1917), que } \\
\text { procuraram estabelecer analogias entre as formas de organização } \\
\text { cultural e social e organizamos vivos. } \\
\text { A consolidação do funcionalismo como método de investigação } \\
\text { social deve-se, entretanto, a Bronislaw Malinowski (1884-1942). }\end{array}$ & $\begin{array}{l}\text { (Gil, 2012, pp. 18- } \\
\text { 19). }\end{array}$ \\
\hline $\begin{array}{c}\text { Método } \\
\text { fenomenológico }\end{array}$ & $\begin{array}{l}\text { O método fenomenológico tem como objetivo descrever, } \\
\text { compreender e interpretar os significados das experiências da vida } \\
\text { humana. Ele se concentra em questões de investigação, tais como } \\
\text { o que é a experiência de uma situação particular. Há uma distinção } \\
\text { a ser feita entre a fenomenologia (que é uma escola filosófica) e } \\
\text { métodos fenomenológicos (que é uma abordagem para a } \\
\text { pesquisa). Fenomenologia tem suas raízes na filosofia e na } \\
\text { psicologia. O método fenomenológico foi apresentado por } \\
\text { Edmund Husserl (1859-1938). }\end{array}$ & (Gil, 2012, p. 14). \\
\hline $\begin{array}{c}\text { Método } \\
\text { experimental }\end{array}$ & $\begin{array}{l}\text { Consiste em submeter os objetos de estudo à influência de certas } \\
\text { variáveis em condições controladas e conhecidas pelo } \\
\text { investigador, para observar os resultados que a variável produz no } \\
\text { objeto. }\end{array}$ & (Gil, 2012, p. 16). \\
\hline $\begin{array}{c}\text { Método } \\
\text { observacional }\end{array}$ & $\begin{array}{l}\text { Pesquisa observacional (ou pesquisa de campo) é uma técnica de } \\
\text { pesquisa social que envolve a observação direta dos fenômenos } \\
\text { em seu ambiente natural. Isso o diferencia da pesquisa } \\
\text { experimental em que um ambiente quase artificial é criado para } \\
\text { controlar fatores espúrios, e onde pelo menos uma das variáveis é } \\
\text { manipulada como parte do experimento. } \\
\text { É o método mais utilizado por ser considerado o mais primitivo, e } \\
\text { consequentemente o mais impreciso. }\end{array}$ & $\begin{array}{l}\text { (Richardson, 2010, } \\
\text { p. 260; Gil, 2012, p. } \\
\text { 16). }\end{array}$ \\
\hline
\end{tabular}


Fonte: Adaptado para a revisão.

As bases filosóficas são a concepção do mundo que explicam cientificamente a natureza e a sociedade, estabelecendo as leis de seu desenvolvimento e a maneira de conhecê-las. Todos os posicionamentos idealistas, que reconhecem o princípio espiritual como primeiro, e a matéria como aspecto secundário, podem ser reduzidos a dois tipos: os que estão representados pelo idealismo subjetivo e o outro, cujos pensamentos defendem o que se denomina idealismo objetivo (Triviños, 2008).

Isso nos remete aos teóricos da corrente funcionalista Gibson Burrell e Gareth Morgan em sua obra Sociological paradigms and organizational analysis. Os autores definem duas dimensões e quatro paradigmas que caracterizam diferentes visões da teoria social. Uma dimensão subjetiva-objetiva, outra da regulação-mudança radical e quatro paradigmas: radical-humanista, radical estruturalista, interpretativo e funcionalista (Burrell \& Morgan, 1979).

Figura 1. Quatro paradigmas para análise da teoria social.

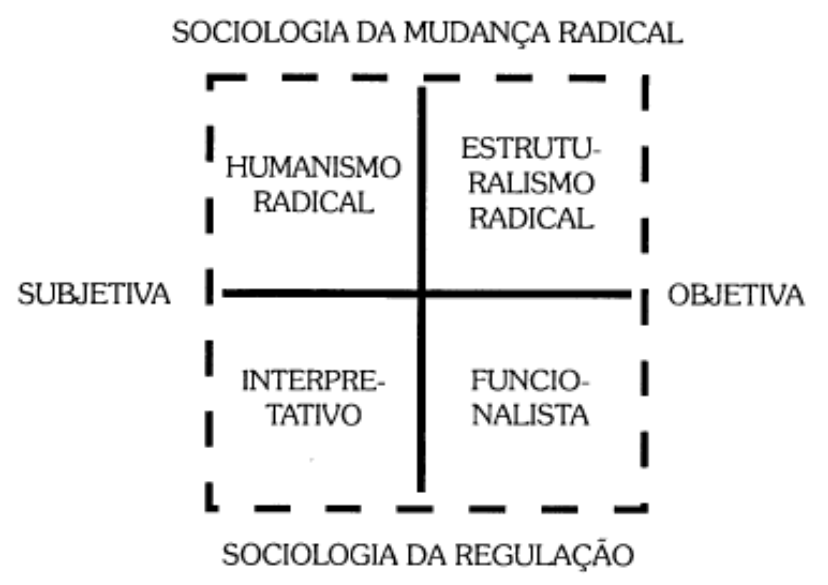

Fonte: Burrel e Moragan, (1979, p. 22).

Os quatro paradigmas definem fundamentalmente diferentes perspectivas para a análise dos fenômenos sociais. Aproximam esse esforço de pontos de vista contrários e dão origem a diferentes conceitos e instrumentos de análise (D’Azevedo, 1994). Os quatro paradigmas fornecem um mapa como uma ferramenta para estabelecer onde você está, onde você esteve e onde é possível ir no futuro (Burrell \& Morgan, 1979).

Os idealistas subjetivos, em geral, parecem duvidar de que o homem seja capaz de conhecer a coisa em si, a essência das coisas. Os idealistas objetivos acham que é possível conhecer o mundo. Uma dicotomia aparente, a da teoria da prática, é resolvida, parece-nos, adequadamente pelo materialismo dialético. Entre os fundamentos dos métodos de procedimento de investigação, a quantificação dos fenômenos sociais apoia-se no positivismo e, naturalmente, também no empirismo. As posições qualitativas baseiam-se especialmente na fenomenologia e no marxismo (Triviños, 2008).

O materialismo dialético é uma forma de entender a realidade, é um método de pensar e interpretar a natureza do mundo e da sociedade. É uma maneira de olhar para o universo, que define a partir do axioma de que tudo está em um estado constante de mudança. A dialética explica que a mudança e o movimento envolvem contradição e só podem ter lugar através das contradições. A dialética é a lógica da contradição (Cornforth, 1968; Voloshinov, 1973; Lefebvre, 2009). Já o idealismo filosófico é aquele que insiste que apenas ideias, espírito, ou 
mente são reais, isso contrasta com o naturalismo que começa com a natureza, a matéria, constituídos de átomos que são a base da realidade (Roark, 1982).

O idealismo significa que não há mais vida e um universo de aparências. O idealismo como filosófico, como tal, afirma que a realidade que se encontra fora da própria mente não é cognoscível por si só, já que o objeto do conhecimento humano é sempre construído pela atividade cognoscitiva(Marcuschi, 2002). A matéria como aspecto secundário, pode ser reduzida a dois tipos: representadas pelo idealismo subjetivo e o idealismo objetivo (Triviños, 2008).

O idealismo subjetivo, representado por Berkeley, é uma visão filosófica baseada na ideia de que nada existe a não ser através da percepção da mente. O mundo só existe na mente daqueles que o percebem, é o conjunto de suas sensações, de suas vivências (Roark, 1982; Berkeley, 1996).O pensamento de Berkeley é o que melhor descreve o idealismo subjetivo. Essa linha de pensamento idealista tem, no século XX, importantes representantes, a maioria situada no Positivismo como Mach, Avenarius, na filosofia da vida Nietzsche, Spengler, Bergson; no pragmatismo encontramos Quince, Goodman, White, e no existencialismo, Heidegger, Sartre, Jaspers e outros (Triviños, 2008).Por sua vez, o idealismo objetivo doutrina de que as coisas materiais não existem. Segundo ele as pessoas podem conhecer apenas aparências sensíveis, enquanto as coisas em si são indescritíveis. Podemos conhecer a realidade supra sensível por pura intuição ou pensamento, independente de sentido (Roark, 1982). Schelling e Hegel representantes do idealismo objetivo chegaram à conclusão de que existe uma única explicação do mundo, o espírito e o absoluto. O espírito é tudo que existe, e torna-se concreto na natureza, ou no homem. O absoluto se manifesta nas partes ou nas subunidades e dessa forma torna-se concreto(Roark, 1982). Para Hegel, o espírito é conhecido como autoconsciência e esta autoconsciência é revelada diretamente, pois é esta a própria autoconsciência. A natureza divina é o mesmo que o ser humano e é essa unidade que é intuitivamente apreendida (Hegel, 1931). O idealismo objetivo apresenta-se em várias correntes filosóficas, especialmente no personalismo e no neotomismo; em geral o idealismo objetivo dá apoio às ideias que constituem os princípios básicos das religiões (Triviños, 2008).

As diferentes perspectivas do idealismo só podem ser compreendidas a partir de sua verdade espiritual, mental ou subjetiva. Seus opostos são representados pelo materialismo filosófico (McGinn, 1980). O materialismo filosófico apoia-se nas conclusões da ciência para explicar o mundo (Triviños, 2008), e postula que tudo é ou pode ser explicado em relação à matéria (Philips, 2003). O progresso da ciência permitiu a Marx e Engels colocarem as bases do materialismo dialético e histórico que se constitui após a metade do século XIX (Triviños, 2008), já definidos na revisão.

Os principais pressupostos que caracterizam diferentes abordagens à teoria social assumem a forma de um debate entre a sociologia interpretativa e funcionalista. Na esteira de Berger e Luckamann (1967) tratando sobre a sociologia do conhecimento, a obra de Garfinkel em etnometodologia (2003) e o ressurgimento do interesse geral na fenomenologia. Da mesma forma, dentro do contexto da sociologia da mudança radical. O debate entre essas duas sociologias caracterizou o início da década de 1960 e foi substituído por um diálogo dentro de um contexto de escolas distintas de pensamento. Cada um dos paradigmas, que pode ser visualizado na Figura 1, compartilha um conjunto comum de recursos com os seus vizinhos sobre os eixos horizontais e verticais. Os quatro paradigmas definem fundamentalmente diferentes perspectivas para a análise dos fenômenos sociais (Burrell \& Morgan, 1979). 
Ao longo da história da ciência surgiram diversas correntes de pensamento, como o empirismo, o materialismo dialético, o positivismo, a fenomenologia, o estruturalismo, e diversos marcos interpretativos como a etnografia e o construtivismo, que deram origem a diferentes caminhos na busca do conhecimento. Ambos os enfoques empregam processos cuidadosos, metódicos e empíricos em seu esforço para gerar conhecimento (Sampieri, Callado, \& Lucio, 2013).

$\mathrm{Na}$ escolha da pesquisa qualitativa, o inquiridor deve fazer certas suposições. Esses pressupostos filosóficos consistem em uma posição em relação à natureza da realidade (ontologia), como o pesquisador sabe o que ela ou ele sabe (epistemologia), o papel dos valores na pesquisa (axiologia), a linguagem da pesquisa (retórica), e os métodos utilizados no processo (metodologia) (Cresswell, 2003). Estes pressupostos são mostrados na Tabela 3.

Tabela 3

Pressupostos filosóficos com implicações para a prática da pesquisa

\begin{tabular}{|c|c|c|c|}
\hline Suposição & Pergunta & Característica & $\begin{array}{c}\text { Implicações para a Prática } \\
\text { (exemplo) }\end{array}$ \\
\hline Ontológica & $\begin{array}{l}\text { Qual é a natureza } \\
\text { da realidade? }\end{array}$ & $\begin{array}{l}\text { A realidade é subjetiva e } \\
\text { múltipla, como vista pelos } \\
\text { participantes do estudo. }\end{array}$ & $\begin{array}{l}\text { O pesquisador usa citações e temas em } \\
\text { palavras dos participantes e fornece } \\
\text { evidências de diferentes perspectivas }\end{array}$ \\
\hline Epistemológica & $\begin{array}{l}\text { Qual é a relação } \\
\text { entre o pesquisador } \\
\text { e o que está sendo } \\
\text { pesquisado? }\end{array}$ & $\begin{array}{l}\text { O pesquisador tenta diminuir } \\
\text { a distância entre si e o que } \\
\text { está sendo pesquisado. }\end{array}$ & $\begin{array}{l}\text { O pesquisador colabora, passa o } \\
\text { tempo no campo com os participantes, } \\
\text { e torna-se um informante. }\end{array}$ \\
\hline Axiológica & $\begin{array}{l}\text { Qual é o papel dos } \\
\text { valores? }\end{array}$ & $\begin{array}{l}\text { O pesquisador reconhece que } \\
\text { a pesquisa é valorativa e que } \\
\text { preconceitos estão presentes. }\end{array}$ & $\begin{array}{l}\text { O pesquisador discute abertamente os } \\
\text { valores que moldam a narrativa e } \\
\text { inclui a sua própria interpretação em } \\
\text { conjunto com as interpretações dos } \\
\text { participantes. }\end{array}$ \\
\hline Retórica & $\begin{array}{llr}\text { O que } & \text { é } & \text { a } \\
\text { linguagem } & & \text { da } \\
\text { pesquisa? } & & \end{array}$ & $\begin{array}{l}\text { O pesquisador escreve num } \\
\text { estilo informal literário } \\
\text { usando a voz pessoal, e } \\
\text { termos qualitativos e } \\
\text { definições limitadas. }\end{array}$ & $\begin{array}{l}\text { O pesquisador usa um estilo } \\
\text { envolvente de narrativa, pode usar } \\
\text { primeira pessoa, pronome, e emprega } \\
\text { a linguagem da pesquisa qualitativa. }\end{array}$ \\
\hline Metodológica & $\begin{array}{l}\text { Qual é o processo } \\
\text { de pesquisa? }\end{array}$ & $\begin{array}{l}\text { O pesquisador usa a lógica } \\
\text { indutiva, estuda o tema } \\
\text { dentro do seu contexto, e usa } \\
\text { um design emergente. }\end{array}$ & $\begin{array}{l}\text { O pesquisador trabalha com } \\
\text { informações (detalhes) antes de } \\
\text { generalizações, descreve em detalhes } \\
\text { o contexto do estudo e revisa } \\
\text { continuamente perguntas } \\
\text { experiências no campo. }\end{array}$ \\
\hline
\end{tabular}

Fonte: Creswell (2007, p. 17).

Em geral, a ciência é uma poderosa ferramenta de convicção (Richardson, 2010), fazendo uso de cinco fases similares e relacionadas entre si que (Grinnell, 1997; Sampieri, Callado, \& Lucio, 2013). Os pesquisadores:

a. Realizam a observação e a avaliação de fenômenos;

b. Criam suposições ou ideias como consequência da observação e da avaliação realizadas;

c. Demonstram o quanto as suposições ou as ideias têm fundamento;

d. Revisam essas suposições ou ideias baseando-se nas provas ou na análise;

e. Propõem novas observações e avaliações para esclarecer, modificar e fundamentar as suposições e ideias ou até para gerar outras.

As abordagens qualitativa e quantitativa compartilham essas estratégias gerais, mas cada uma possui suas próprias características (Sampieri, Callado, \& Lucio, 2013). As ciências sociais até o momento não se consolidaram como as ciências do tipo apenas positivo, como aconteceu com 
outras ciências. A adoção de metodologia quantitativa não significa necessariamente rigor, como a qualitativa não significa necessariamente inexatidão e pura conjectura. A tradição do realismo aristotélico, assim como do criticismo kantiano, incluem a quantidade e a qualidade como dimensões constitutivas do real (Bertero, 2013).

\subsection{Subsídio da Pesquisa Qualitativa}

A definição considerada por muitos uma contribuição oficial sobre a metodologia da pesquisa qualitativa é apresentada por Denzin e Lincoln (2005) que definem a pesquisa qualitativa como vários métodos em foco, envolvendo uma abordagem interpretativa, naturalista do assunto em estudo. Isso significa que os pesquisadores qualitativos estudam as coisas em seus ambientes naturais, tentando dar sentido ou interpretar fenômenos em termos dos significados que as pessoas dão a eles. A pesquisa qualitativa envolve o uso de uma variedade de materiais empíricos - estudo de caso, experiência pessoal, introspectivo, história de vida, entrevista, textos observacionais, históricos, interacionais e visuais - que descrevem momentos e significados rotineiros e problemáticos na vida dos indivíduos (Denzin \& Lincoln, 2005).

A pesquisa qualitativa pode ser caracterizada como a tentativa de uma compreensão detalhada dos significados e características situacionais apresentadas pelos entrevistados, em lugar da produção de medidas quantitativas de características ou comportamentos (Richardson, 2010). O objetivo da pesquisa qualitativa é desenvolver conceitos que melhorem a compreensão dos fenômenos sociais em ambientes naturais, com a devida ênfase nos significados, experiências e pontos de vista de todos os participantes (Neergaard \& Ulhoi, 2007).

A pesquisa qualitativa preocupa-se em analisar e interpretar aspectos mais profundos, descrevendo a complexidade do comportamento humano. Fornece análise mais detalhada sobre as investigações, hábitos, atitudes, tendências de comportamento etc. (Lakatos \& Marconi, 2011).

Alguns autores entendem a pesquisa qualitativa como uma expressão genérica pela dificuldade do entendimento à abrangência do conceito e os limites da investigação, e principalmente, dos suportes teóricos fundamentais que alimentam a pesquisa qualitativa (Triviños, 2008).

A abordagem qualitativa, além de ser uma opção do investigador, justifica-se, sobretudo, por ser uma forma adequada para entender a natureza de um fenômeno social. $\mathrm{O}$ objeto qualitativo de uma investigação pode estar presente até mesmo nas informações colhidas por estudos essencialmente qualitativos, não obstante perderem seu caráter qualitativo quando transformados em dados quantificáveis, na tentativa de assegurar a exatidão no plano dos resultados (Richardson, 2010).

O emprego da abordagem qualitativa dá-se quando queremos ir além da mera descrição em um nível generalizado nas nossas investigações empíricas. Abordagens qualitativas e quantitativas são frequentemente apresentadas como adversárias em uma batalha metodológica. No entanto, mesmo dentro de uma pesquisa qualitativa uma batalha semelhante está ocorrendo. Basicamente, os pesquisadores qualitativos adotam duas abordagens opostas. Por um lado, há aqueles que estão totalmente comprometidos com o uso de métodos qualitativos e defendemnos na medida em que eles podem cavar novas trincheiras para sustentar o paradigma da pesquisa qualitativa diante da pesquisa quantitativa. Todavia, há aqueles que escolhem entre métodos qualitativos e quantitativos de acordo com o tema de interesse e as questões de investigação relacionadas (Brannen, 1992; Neergaard \& Ulhoi, 2007). 
Figura 2. Enfoque da pesquisa qualitativa

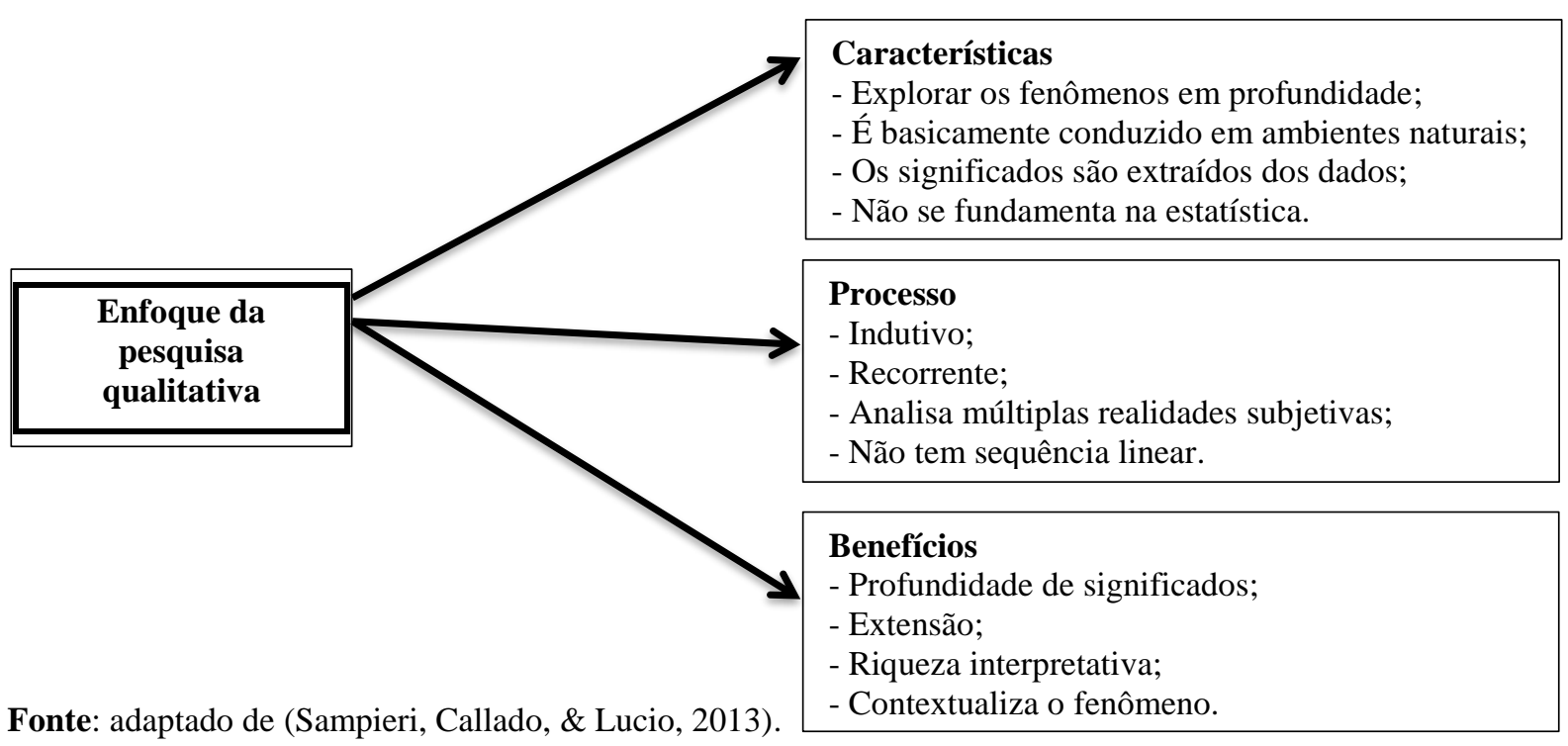

A pesquisa qualitativa utiliza a coleta de dados sem medição numérica para descobrir ou aprimorar perguntas de pesquisa no processo de interpretação. No enfoque qualitativo a clareza das perguntas da pesquisa e das hipóteses deve vir antes da coleta e da análise dos dados; nos estudos qualitativos é possível desenvolver perguntas e hipóteses antes, durante e depois da coleta e da análise dos dados. Geralmente, essas atividades servem para primeiro descobrir quais são as perguntas de pesquisa mais importantes, e depois, para aprimorá-las e respondêlas. A ação indagativa se move de maneira dinâmica em ambos os sentidos: entre fatos e sua interpretação, e é um processo mais circular no qual a sequência nem sempre é a mesma, ela varia de acordo com cada estudo específico (Sampieri, Callado, \& Lucio, 2013).

O desenvolvimento de um estudo qualitativo supõe um corte temporal-espacial de determinado fenômeno por parte do pesquisador (Neves, 1996). Na pesquisa qualitativa há um mínimo de estruturação prévia. Ela não admite regras precisas, como problemas, hipóteses e variáveis antecipadas, e as teorias aplicáveis deverão ser empregadas no decorrer da investigação (Lakatos \& Marconi, 2011).

A pesquisa qualitativa pode empregar vários métodos e técnicas. A escolha depende do tipo de investigação (Lakatos \& Marconi, 2011). Para não se perder no contexto geral que lhe serve de apoio, o investigador necessita, todavia, de um mínimo de estruturação, de embasamento teórico geral e de um planejamento cuidadoso (Lakatos \& Marconi, 2011).

A escolha do método remete para uma posição teórica (positivista, estruturalista, dialética, fenomenológica etc.) (Ludke \& André, 1986; Beuren, Longaray, Raupp, \& Batista, 2003; Boni \& Quaresma, 2005; Lakatos \& Marconi, 2011; Bryman, 2012; Bento \& Ferreira, 2013)que compreende a forma de abordagem. A teoria é constituída para explicar ou compreender um fenômeno, um processo ou um conjunto deles (Lakatos \& Marconi, 2011).

As características da pesquisa qualitativa para Triviños (2008, pp. 128-30) apresentam as contribuições de Bogdan que compreendem as seguintes características:

i. A pesquisa qualitativa tem o ambiente natural como fonte direta dos dados e o pesquisador como instrumento-chave;

ii. A pesquisa qualitativa é descritiva; 
iii. Os pesquisadores qualitativos estão preocupados com o processo e não simplesmente com os resultados e o produto;

iv. Os pesquisadores qualitativos tendem a analisar seus dados indutivamente;

v. O significado é a preocupação essencial na abordagem qualitativa.

$\mathrm{O}$ pesquisador qualitativo tem ampla liberdade teórico-metodológica para realizar seu estudo. De forma muito geral, a pesquisa qualitativa segue a mesma rota ao realizar uma investigação. Os limites da iniciativa estarão fixados pelas condições da exigência de um trabalho científico (Triviños, 2008).

\subsubsection{Tipos de Pesquisa Qualitativa}

A pesquisa qualitativa envolve o estudo do uso e coleta de uma variedade de materiais empíricos (exemplo: estudo de caso, experiência pessoal, introspecção, história de vida, entrevista, artefatos, textos e produções culturais, textos observacionais, históricos, interativos e visuais) que descrevem momentos e significados rotineiros e problemáticos na vida dos indivíduos (Denzin \& Lincoln, 2006). Existe uma infinidade de literaturas sobre o grande número de métodos e abordagens como pesquisa-ação participativa (Kemmis \& Wilkinson, 1998), a análise do discurso (Cheek, 2004), etnografia (Creswell, 2007), teoria fundamentada em dados (Corbin \& Strauss, 1990; 1998; Charmaz, 2006), estudo de caso (Stake, 1995), pesquisa fenomenológica (Moustakas, 1994), investigação narrativa (Clandinin \& Connelly, 2000).

Os estudos qualitativos apresentam uma gama de opções de abordagens que são examinados pela classificação ou tipologias. Uma das classificações mais populares é fornecida por Tesch (1990), que organizou 28 abordagens em quatro ramos de um fluxograma, separando essas abordagens baseado no interesse central do investigador. A abordagem de Wolcott (1999) classificou os estudos qualitativos em um diagrama de árvore, com ramos das estratégias de designação para a coleta de dados. Já Miller e Crabtree (1992) organizaram 18 tipos de acordo com o domínio da vida humana, principal preocupação para os pesquisadores, o foco no indivíduo, no mundo social ou da cultura (Creswell, 2007). A Tabela 4 lista o sistema de abordagem de pesquisa qualitativa e observa suas raízes interdisciplinares.

Tabela 4. Abordagens qualitativas apontadas pelos autores

\begin{tabular}{|c|c|c|}
\hline Autores & Abordagens Qualitativas & Disciplina / Campo \\
\hline Jacob (1987) & $\begin{array}{l}\text { Psicologia Ecológica } \\
\text { Etnografia Holística } \\
\text { Antropologia Cognitiva } \\
\text { Etnografia da Comunicação } \\
\text { Interacionismo simbólico. }\end{array}$ & Educação \\
\hline Munhall e Oiler (1986) & $\begin{array}{l}\text { Fenomenologia } \\
\text { Teoria fundamentada em dados } \\
\text { Etnografia } \\
\text { Pesquisa Histórica. }\end{array}$ & Enfermagem \\
\hline Lancy(1993) & $\begin{array}{l}\text { Perspectivas antropológicas } \\
\text { Perspectivas sociológicas } \\
\text { Perspectivas biológicas } \\
\text { Estudos de caso } \\
\text { Contas pessoais } \\
\text { Estudos Cognitivos } \\
\text { Investigações históricas. }\end{array}$ & Educação \\
\hline Corbin e Strauss(1990) & $\begin{array}{l}\text { Teoria fundamentada em dados etnografia } \\
\text { Fenomenologia } \\
\text { Histórias de vida } \\
\text { Análise da Conversação }\end{array}$ & Sociologia/ enfermagem \\
\hline
\end{tabular}




\begin{tabular}{|c|c|c|}
\hline Morse (1994) & $\begin{array}{l}\text { Fenomenologia } \\
\text { Etnografia } \\
\text { Etnociência } \\
\text { Teoria fundamentada em dados. }\end{array}$ & Enfermagem \\
\hline Moustakas(1994) & $\begin{array}{l}\text { Etnografia } \\
\text { Teoria fundamentada em dados } \\
\text { Hermenêutica } \\
\text { Pesquisa fenomenológica empírica } \\
\text { Pesquisa heurística } \\
\text { Fenomenologia Transcendental }\end{array}$ & Psicologia \\
\hline Denzin e Lincoln (1994) & $\begin{array}{l}\text { Estudos de caso } \\
\text { Etnografia } \\
\text { Fenomenologia } \\
\text { Etnometodologia } \\
\text { Práticas interpretativas } \\
\text { Teoria fundamentada em dados } \\
\text { Biográfico } \\
\text { Histórico } \\
\text { Pesquisa Clínica }\end{array}$ & Ciências sociais \\
\hline Miles e Huberman (1994) & $\begin{array}{l}\text { Abordagens Qualitativa } \\
\text { Teoria fundamentada em dados } \\
\text { Interpretativismo } \\
\text { Antropologia Social } \\
\text { Colaboração Pesquisa Social }\end{array}$ & Ciências sociais \\
\hline Slife e Williams (1995) & $\begin{array}{l}\text { Categorias de métodos qualitativos } \\
\text { Etnografia } \\
\text { Fenomenologia } \\
\text { Estudos de artefatos. }\end{array}$ & Psicologia \\
\hline Denzin e Lincoln (2005) & $\begin{array}{l}\text { Desempenho, crítico e } \\
\text { Etnografia pública } \\
\text { Práticas interpretativas } \\
\text { Estudos de caso } \\
\text { Teoria fundamentada em dados } \\
\text { História de Vida } \\
\text { Narrativa Autoridade } \\
\text { Pesquisa-ação participativa } \\
\text { Pesquisa Clínica. }\end{array}$ & Ciências sociais \\
\hline
\end{tabular}

Fonte: Creswell (2007, pp. 7-8).

A pesquisa qualitativa abrange uma ampla variedade de abordagens, mas, por definição, nenhuma dessas abordagens baseia-se em medições numéricas (Creswell, 2007). Em linhas gerais, a pesquisa qualitativa não procura enumerar e/ou medir os eventos estudados, nem emprega instrumental estatístico na análise dos dados. Parte de questões ou focos de interesse amplo, que vão se definindo à medida que o estudo se desenvolve. Envolve a obtenção de dados descritivos sobre pessoas, lugares e processos interativos pelo contato direto do pesquisador com a situação estudada, procurando compreender os fenômenos segundo a perspectiva dos sujeitos, ou seja, dos participantes da situação em estudo (Godoy A. S., 1995). A pesquisa tende a se concentrar em um ou um pequeno número de casos, para usar entrevistas intensivas ou análise aprofundada dos materiais históricos, para ser discursiva no método, e preocupar-se em dar conta de forma abrangente de um evento ou unidade. Mesmo que eles tenham um pequeno número de casos, os pesquisadores qualitativos geralmente descobrem enormes quantidades de informação a partir de seus estudos. Às vezes, esse tipo de trabalho nas ciências sociais está relacionado com a área ou estudos de caso onde o foco está em um evento particular, a decisão, a instituição, localização, problema, ou uma parte de um evento (Creswell, 2007). 
Sob a denominação pesquisa qualitativa encontram-se variados tipos de investigação, apoiados em diferentes quadros de orientação teórica e metodológica (Godoy A. S., 1995), tais como apresentados no Quadro 4. Essa diversidade de enfoques muitas vezes confunde e dificulta a leitura de livros, obras de referência e artigos de pesquisa na área (Godoy A. S., 1995).

A abordagem e o método qualitativo oferecem o uso e a coleta de uma variedade de possibilidades de se realizar pesquisa qualitativa. Diferentes autores têm discutido os métodos de coleta de dados qualitativos de forma diferente. Patton (2002), Denzin e Lincoln (2011) e Merriam (1998) identificaram diversos tipos diferentes de métodos de pesquisa qualitativa como: estudo de caso, etnografia, fenomenologia, históricos, pesquisa-ação, análise de conteúdo, teoria fundamentada em dados, método qualitativo genérico, pesquisa documental, experiência pessoal, introspecção, história de vida, entrevista, artefatos, textos e produções culturais, textos observacionais, interativos e visuais, análise do discurso e investigação narrativa.

Tabela 5

Métodos de pesquisa qualitativa

\begin{tabular}{|c|c|}
\hline Estudo de caso $^{1}$ & $\begin{array}{l}\text { As tentativas de lançar luz sobre um fenômeno, estudando em profundidade a } \\
\text { exemplo de caso único dos fenômenos. O caso pode ser uma } \\
\text { pessoa individual, um evento, um grupo ou uma instituição. }\end{array}$ \\
\hline Etnografia & $\begin{array}{l}\text { Concentra-se e na sociologia do significado através da observação de campo perto de } \\
\text { fenômeno socioculturais. Normalmente, o etnógrafo se concentra em uma comunidade. } \\
\text { É a arte e a ciência de descrever um grupo humano, suas intuições, seus } \\
\text { comportamentos interpessoais, suas produções materiais e suas crenças. }\end{array}$ \\
\hline Fenomenologia & $\begin{array}{l}\text { Descreve as estruturas de experiência como eles se apresentam à consciência, sem } \\
\text { recorrer à teoria, dedução ou hipóteses de outras disciplinas. É o estudo das estruturas } \\
\text { da vida social conhecidas através da descrição analítica dos atos de consciência } \\
\text { intencional. }\end{array}$ \\
\hline Históricos & $\begin{array}{l}\text { Recolha sistemática e avaliação objetiva dos dados relativos às ocorrências passadas, a } \\
\text { fim de testar hipóteses sobre causas, efeitos ou tendências desses eventos que podem } \\
\text { ajudar a explicar os acontecimentos atuais e antecipar eventos futuros. }\end{array}$ \\
\hline Pesquisa-Ação & $\begin{array}{l}\text { A pesquisa-ação é o inquérito ou investigação no contexto dos esforços voltados para } \\
\text { melhorara qualidade da prática e normalmente é concebido e realizado por profissionais } \\
\text { que analisam os dados para melhorar a sua própria prática. } \\
\text { A pesquisa-ação é uma forma de estudo com características muito específicas e que } \\
\text { envolve o pesquisador e os membros de uma organização no trabalho de análise de um } \\
\text { assunto que seja de genuíno interesse dos participantes em agir com base na intervenção } \\
\text { e mudança propostas. É uma proposta intervencionista de pesquisa, preocupada com as } \\
\text { práticas inseridas em um contexto específico, requerentes por melhorias, por mudanças. }\end{array}$ \\
\hline Análise de Conteúdo & $\begin{array}{l}\text { A análise de conteúdo é usada para determinara presença de certas palavras ou conceitos } \\
\text { dentro de textos ou conjuntos de textos. Pesquisadores quantificam e analisam a }\end{array}$ \\
\hline
\end{tabular}

\footnotetext{
${ }^{1}$ Estudo de caso: o estudo de caso é uma categoria de pesquisa cujo objeto é uma unidade que se analisa profundamente (Triviños, 2008). Os estudos de caso são análises de pessoas, eventos, decisões, períodos, projetos, políticas, instituições, ou outros sistemas que são estudados de forma holística por um ou mais métodos de caso em que é o assunto do inquérito que será uma instância de uma classe de fenômenos que fornece um quadro analítico - um objeto - dentro do qual o estudo é realizado e que o caso ilumina e explicita (Thomas, 2011). Entre os usos persistentes de dados ilustrativos são histórias de vida e biografias, narrativas recolhidas através de entrevistas com os entrevistados sobre suas vidas. Estes são, no entanto, apenas uma forma de história do caso. A principal característica de todas as histórias de casos é que eles cobrem algum espaço temporal, ou interlúdio na vida social - uma biografia, uma carreira profissional, um projeto, uma doença, um desastre, uma cerimônia. Além disso, o histórico do caso envolve uma história sobre uma unidade social - uma pessoa, grupo, organização, relacionamento. É útil distinguir histórias de casos a partir de estudos de caso. Na construção do último, o pesquisador está focado em abstrações analíticas para fins de apresentar a teoria em algum nível ou outro.

Um grande número de publicações de pesquisadores qualitativos é escrito na forma de estudos de caso, como na representação analítica de vários tipos de grupos, organizações e culturas. Os estudos de caso podem ser prospectivos (em que os critérios são estabelecidos e casos ajustados aos critérios incluídos assim que estiverem disponíveis) ou retrospectivos (em que são estabelecidos critérios para a seleção de casos a partir de registros históricos para a inclusão no estudo) (Yin, 2009). Os dados qualitativos descrevem detalhadamente os indivíduos ou grupos em sua própria terminologia (Lakatos \& Marconi, 2011).

(Lakatos \& Marconi, 2011) pautados em Ludke e André (1986) apresentam algumas características fundamentais do estudo de caso como: (i) Visar a descoberta, (ii) Enfatizar a interpretação do contexto, (iii) Retratar a realidade de forma ampla, (iv) Valer-se de fontes diversas de informações, (v) Permitir substituições, (vi) Representar diferentes pontos de vista em dada situação, (vii) Usar linguagem simples.
}

UFAMBR, Manaus, v. 2, n. 3, art. 6, pp. 103-130, julho-dezembro, 2020 http://www.periodicos.ufam.edu.br/ufambr 


\begin{tabular}{|c|c|}
\hline & $\begin{array}{l}\text { presença, significados e relações de tais palavras e conceitos, em seguida, fazem } \\
\text { inferências sobre as mensagens dentro dos textos sobre o (s) escritor (es), o público, e } \\
\text { até mesmo a cultura e o tempo de que estes são uma parte. }\end{array}$ \\
\hline Análise de dados & $\begin{array}{l}\text { Análise de dados é descrita com mais precisão como método de pesquisa em que a teoria } \\
\text { é desenvolvida a partir dos dados, ao invés do contrário. Isso faz com que ela seja uma } \\
\text { abordagem indutiva, o que significa que se move a partir do específico para o mais } \\
\text { geral. }\end{array}$ \\
\hline $\begin{array}{l}\text { Método qualitativo } \\
\text { genérico }\end{array}$ & $\begin{array}{l}\text { O método qualitativo genérico não tem um conjunto de pressupostos filosóficos como } \\
\text { guia na forma de uma das metodologias qualitativas estabelecidas. }\end{array}$ \\
\hline Pesquisa documental & $\begin{array}{l}\text { Pesquisa documental envolve o uso de textos e documentos como matérias-primas. Os } \\
\text { materiais de base incluem: publicações do governo, jornais, certificados, publicações } \\
\text { do censo, romances, filmes e vídeos, pinturas, fotografias pessoais, diários e outras } \\
\text { fontes visuais e pictóricas, inúmeros escritos em papel, em formato eletrônico ou outro } \\
\text { tipo de cópia. }\end{array}$ \\
\hline Etnometodologia & $\begin{array}{l}\text { É o estudo dos métodos da vida cotidiana. Os estudos etnometodológicos são } \\
\text { direcionados para as tarefas de aprendizagem dos membros, onde as atividades } \\
\text { consistem em métodos que tornam as ações práticas, as circunstâncias práticas e o } \\
\text { conhecimento do senso comum das estruturas sociais em práticas analisáveis pelo } \\
\text { raciocínio sociológico prático. }\end{array}$ \\
\hline $\begin{array}{l}\text { Teoria } \\
\text { fundamentada em } \\
\text { dados }\end{array}$ & $\begin{array}{l}\text { Usa uma técnica de trabalho que consiste em uma abordagem de pesquisa que visa a } \\
\text { desenvolver teorias a partir de conceitos e relações baseadas nos dados coletados, ao } \\
\text { invés de utilizar aquelas predeterminadas, e compreende a realidade a partir do } \\
\text { conhecimento, sentido ou significado que certo contexto ou objeto tem para as pessoas. } \\
\text { É um método que apresenta certa semelhança com os demais métodos qualitativos, tais } \\
\text { como a etnografia e a fenomenologia, onde há uma forte ênfase na subjetividade da } \\
\text { realidade construída no âmago dos sujeitos pesquisados, apoiado pela capacidade } \\
\text { crítica-reflexiva do pesquisador enquanto condutor parcial do processo de investigação. }\end{array}$ \\
\hline
\end{tabular}

Fonte: adaptado de Merriam(1998), Patton(2002), DenzineLincoln(2011), Mendonça (2013), Franzolin(2013).

A pesquisa qualitativa começa por aceitar que há muitas maneiras diferentes de compreensão e de dar sentido ao mundo. Em resumo, a pesquisa qualitativa se preocupa com os aspectos sociais do nosso mundo (Bogdan \& Biklen, 1998).

Para se começar uma pesquisa, o propulsor para um estudo é a definição do problema, pois sem ele não há razão de realizar a pesquisa (Vera, 1979). A Figura 3 apresenta o processo qualitativo da pesquisa, que inicia com o pesquisador formulando um problema até a sua fase final.

Figura 3. Características do enfoque qualitativo

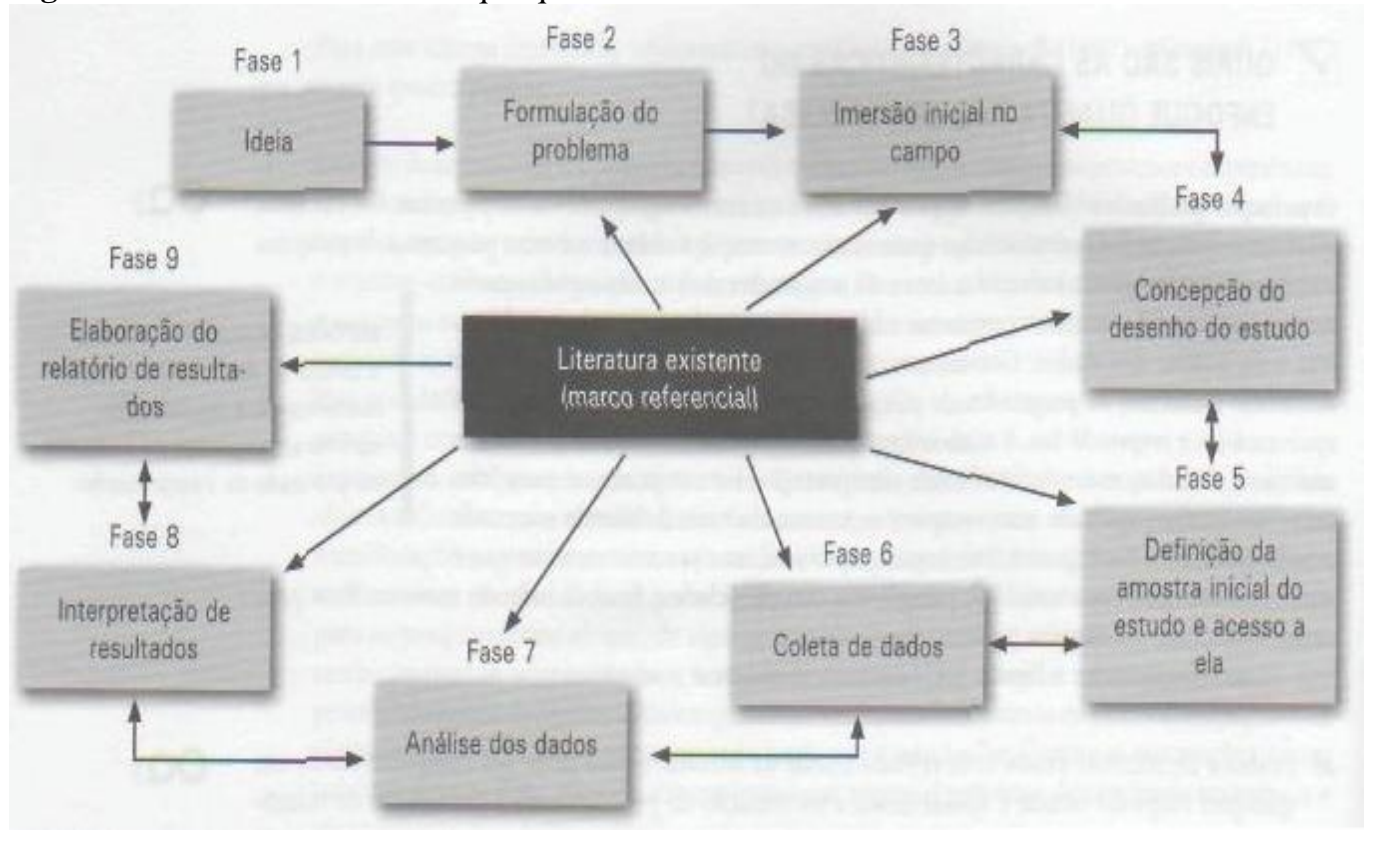

UFAMBR, Manaus, v. 2, n. 3, art. 6, pp. 103-130, julho-dezembro, 2020 http://www.periodicos.ufam.edu.br/ufambr 
Fonte: (Sampieri, Callado, \& Lucio, 2013, p. 34).

A sucessão dessas fases nem sempre é rigorosamente observada, podendo ocorrer que algumas delas não apareçam claramente em muitas pesquisas. Contudo, esse encadeamento de fases parece ser o mais lógico (Gil, 2012).Além disso, a pesquisa qualitativa pode empregar vários métodos e técnicas. A escolha depende do tipo de investigação (Lakatos \& Marconi, 2011).

\subsubsection{Técnicas Fundamentais de Coleta De Dados}

A coleta de dados para a pesquisa qualitativa geralmente implica interagir com situações do mundo real e as pessoas nele. Todos se tornam parte do cenário de campo para um estudo de pesquisa. A variedade de configurações de campo contribui para os inúmeros eventos humanos importantes e interessantes que podem se tornar objeto de estudos qualitativos. Ao mesmo tempo, porque as configurações de campo são situações do mundo real, os pesquisadores precisam entrar e sair dele com alguma formalidade, em especial, a obtenção das permissões necessárias para fazer o seu estudo. Manter relacionamentos saudáveis de campo torna-se então um desafio permanente (Yin, 2010).

Os dados ${ }^{2}$ servem como base para um estudo de pesquisa(Yin, 2010).As técnicas de coleta de dados mais utilizadas em pesquisa qualitativas são: observação, entrevista e história de vida (Lakatos \& Marconi, 2011), questionário, escalas sociais, utilização de documentos, análise e interpretação e relatório de pesquisa (Yin, 2010).

A coleta de dados é um aspecto importante de qualquer tipo de estudo de pesquisa. Coleta de dados imprecisos podem impactar os resultados de um estudo e, finalmente, levar a resultados inválidos (Ramsden \& Moses, 1992; Creswell \& Clark, 2007; Fraenkel, Wallen, \& Hyun, 2019). A Tabela 6 descreve as principais técnicas utilizadas na pesquisa qualitativa.

Tabela 6. Técnicas fundamentais de coleta de dados

\begin{tabular}{|c|c|}
\hline $\begin{array}{l}\text { Técnicas de } \\
\text { coleta de dados }\end{array}$ & Metodologia qualitativa \\
\hline Observação & $\begin{array}{l}\text { A observação é uma técnica de coleta de dados para conseguir informações utilizando os } \\
\text { sentidos na obtenção de determinados aspectos da realidade. Não consiste em apenas ver e } \\
\text { ouvir, mas também em examinar fatos ou fenômenos que se deseja estudar (Lakatos \& } \\
\text { Marconi, 2011). } \\
\text { A observação pode ser estruturada ou não estruturada. O grau de participação do } \\
\text { observador, que pode ser ativa ou passiva, combina os seguintes critérios: (i) observação } \\
\text { simples, (ii) observação participante, (iii) observação sistemática (Gil, 2012). } \\
\text { Participação simples é aquela em que o pesquisador permanece alheio à comunidade, grupo } \\
\text { ou situação que pretende estudar. Observação participante consiste na participação real do } \\
\text { conhecimento na vida da comunidade, do grupo ou de uma situação determinada. } \\
\text { Observação sistemática é frequentemente utilizada em pesquisa que tem como objetivo a } \\
\text { descrição precisa dos fenômenos ou teste de hipótese (Gil, 2012). }\end{array}$ \\
\hline & $\begin{array}{l}\text { A entrevista é, sem dúvida, a fonte mais comum de obtenção de dados em estudos } \\
\text { qualitativos. O formato de pessoa-a-pessoa é mais prevalente, mas, ocasionalmente, } \\
\text { entrevistas em grupo e grupos de discussão são conduzidas. Entrevistas vão desde o estilo } \\
\text { altamente estruturado, em que as questões são determinadas anteriormente. Na pesquisa } \\
\text { qualitativa, o formato altamente estruturado é usado principalmente para reunir } \\
\text { informações sociodemográficas. Para a maior parte, no entanto, as entrevistas são mais } \\
\text { abertas e menos estruturadas(Merriam, 1998). Frequentemente, o entrevistador pergunta as } \\
\text { mesmas perguntas de todos os participantes, mas a ordem das questões, o texto exato e o }\end{array}$ \\
\hline
\end{tabular}

\footnotetext{
${ }^{2}$ Dados refere-se a um conjunto de informações organizadas, normalmente o resultado da experiência, observação, experimentação. ... Isto pode consistir em números, palavras ou imagens, em particular no que medições ou observações de um conjunto de variáveis (Yin, 2010).
} 


\begin{tabular}{|c|c|}
\hline Entrevista & $\begin{array}{l}\text { tipo de perguntas de acompanhamento podem variar consideravelmente (Thomas, Nelson, } \\
\text { \& Silverman, 2015). } \\
\text { Existem três tipos fundamentais de entrevistas de pesquisa: estruturadas, semiestruturadas } \\
\text { e não-estruturadas. Estruturadas - O entrevistador faz ao entrevistado as mesmas perguntas } \\
\text { da mesma forma; um rígido esquema é usado; as perguntas podem ser formuladas de modo } \\
\text { que um número limitado de respostas pode ser dado - ou seja, "você classifica os nossos } \\
\text { serviços como muito bom, bom ou ruim"; um pesquisador precisa considerar se um } \\
\text { questionário estruturado ou se a entrevista é mais apropriada; se o cronograma de entrevista } \\
\text { é muito estruturado isso pode impedir que os fenômenos sob investigação a sejam } \\
\text { explorados em profundidade. Semiestruturadas - entrevistas semiestruturadas são, por } \\
\text { vezes, também chamadas de entrevistas focadas; uma série de perguntas abertas com base } \\
\text { nas áreas de tópico que o pesquisador quer cobrir; uma série de questões amplas para } \\
\text { perguntar e que podem ter algumas instruções para ajudar o entrevistado; a natureza em } \\
\text { aberto das questões define o tema em investigação, mas oferece oportunidades tanto para } \\
\text { o entrevistador e o entrevistado para discutir alguns temas com mais detalhes; entrevistas } \\
\text { semiestruturadas permitem ao pesquisador encorajar o entrevistado; esse método dá ao } \\
\text { pesquisador a liberdade de sondar o entrevistado a elaborar ou a seguir uma nova linha de } \\
\text { investigação introduzida pelo que o entrevistado está dizendo; funcionam melhor quando } \\
\text { o entrevistado tem uma série de áreas que ele/ela precisa resolver. Não-estruturadas: podem } \\
\text { ser referidas como "profundidade" ou entrevistas "em profundidade"; elas têm muita pouca } \\
\text { estrutura; o entrevistador pode ir apenas com o objetivo de discutir um número limitado de } \\
\text { temas, às vezes tão poucos como apenas um ou dois; o entrevistador pode enquadrar as } \\
\text { perguntas da entrevista com base no entrevistado e sua resposta anterior; isso permite a } \\
\text { discussão para cobrir áreas em grande detalhe; elas envolvem o pesquisador querendo saber } \\
\text { ou saber mais sobre um tópico específico sem que haja uma estrutura ou um plano } \\
\text { preconcebido ou expectativa a respeito de como ele vão lidar com o tema(Gill, Stewart, } \\
\text { Treasure, \& Chadwick, 2008). }\end{array}$ \\
\hline História de & $\begin{array}{l}\text { Refere-se a uma narração em torno de determinados fatos ou fenômenos, nos quais se } \\
\text { evidenciam valores e padrões culturais. É uma técnica de coleta que pode complementar } \\
\text { dados já levantados (Lakatos \& Marconi, 2011). } \\
\text { Através da história de vida pode-se captar o que acontece na intersecção do individual com } \\
\text { o social, assim como permitir que elementos do presente fundam-se a evocações passadas. } \\
\text { Podemos, assim, dizer, que a vida olhada de forma retrospectiva faculta uma visão total de } \\
\text { seu conjunto, e que é o tempo presente que torna possível uma compreensão mais } \\
\text { aprofundada do momento passado. A história de vida pode ser, dessa forma, considerada } \\
\text { instrumento privilegiado para análise e interpretação, na medida em que incorpora } \\
\text { experiências subjetivas mescladas a contextos sociais. Ela fornece, portanto, base } \\
\text { consistente para o entendimento do componente histórico dos fenômenos individuais, } \\
\text { assim como para a compreensão do componente individual dos fenômenos históricos. A } \\
\text { história de vida é, geralmente, extraída de uma ou mais entrevistas denominadas entrevistas } \\
\text { prolongadas, nas quais a interação entre pesquisador e pesquisado se dá de forma } \\
\text { contínua(Paulilo, 1999). }\end{array}$ \\
\hline Questionário & $\begin{array}{l}\text { É uma técnica de investigação composta por um conjunto de questões que são submetidas } \\
\text { a pessoas com o propósito de obter informações sobre conhecimentos, crenças, } \\
\text { sentimentos, valores, interesses, expectativas, aspirações, temores, comportamento } \\
\text { presente ou passado etc. (Gil, 2012). Os questionários cumprem a função de descrever as } \\
\text { características e medir determinadas variáveis de um grupo social (Richardson, 2010). } \\
\text { Tipos de questionários segundo Richardson (2010): } \\
\text { Tipo de pergunta } \\
\text { Questionários de perguntas fechadas } \\
\text { Questionários de perguntas abertas } \\
\text { Questionários que combinam perguntas abertas e fechadas } \\
\text { Outros em que os entrevistados tenham mais liberdade de resposta } \\
\text { Aplicação dos questionários } \\
\text { Contato direto e questionário por correio (inclui os meios eletrônicos e outros) }\end{array}$ \\
\hline Escalas sociais & $\begin{array}{l}\text { São instrumentos construídos com o objetivo de medir a intensidade das opiniões e atitudes } \\
\text { da maneira mais objetiva possível. Consistem basicamente em solicitar ao indivíduo } \\
\text { pesquisado que assinale, dentro de uma série graduada de itens, aqueles que melhor } \\
\text { correspondem à sua percepção acerca do fato pesquisado (Gil, 2012). Para Gil (2012) as } \\
\text { escalas mais utilizadas são: }\end{array}$ \\
\hline
\end{tabular}




\begin{tabular}{|c|l|}
\hline & $\begin{array}{l}\text { Escalas de ordenação; escalas de graduação; escalas de distância social; escala de } \\
\text { Thurstone; escala de Likert. }\end{array}$ \\
\hline $\begin{array}{l}\text { É a obtenção de dados indiretos, sem aplicação às pessoas. É a técnica que toma forma de } \\
\text { documentos, livros, jornais, papeis oficiais, registros estatísticos, fotos, discos, filmes e } \\
\text { vídeos, que são obtidos de maneira indireta. A pesquisa documental tradicionalmente vale- } \\
\text { se dos registros cursivos, que são persistentes e continuados (Gil, 2012). Registros }\end{array}$ \\
$\begin{array}{l}\text { Utilização de } \\
\text { episódicos e privados, constituídos por documentos pessoais e por imagens visuais } \\
\text { documentos } \\
\text { produzidas por meios de comunicação em massa. E, também, por pesquisas que se valem } \\
\text { dos chamados dados encontrados, que são constituídos não apenas por objetos materiais, } \\
\text { mas também por vestígios físicos produzidos por erosão ou acumulação no meio ambiente } \\
\text { (Gil, 2012). }\end{array}$ \\
\hline
\end{tabular}

Fonte: adaptado para a revisão

Dentro de cada abordagem geral da pesquisa, podem ser utilizados uma ou mais técnicas de coleta de dados. Normalmente, o pesquisador irá decidir por uma (ou várias) técnica(s) de coleta de dados ao mesmo tempo considerando sua adequação global a pesquisa, juntamente com outros fatores práticos, tais como: qualidade esperada dos dados coletados, os custos estimados, previsão de taxas de não resposta, nível esperado em medir os erros, e duração do período de coleta de dados (Lyberg \& Kasprzyk, 2004). As técnicas de coleta de dados mais populares estão apresentadas no Quadro 6.

\subsubsection{Análise e Interpretação}

A análise e interpretação de dados é a fase seguinte à coleta de dados. É a análise e a interpretação dos dados coletados (Gil, 2012). É a fase da análise qualitativa em transformar dados em resultados (Patton, 2002). O investigador atua como catalisador em dados brutos, gerando uma interação que sintetiza uma nova substância viva da conversão catalítica. Os resultados surgem como um mural artístico criado a partir de partes da colagem que fazem sentido em novas formas quando vistas e entendidas como parte de um todo maior. A transformação, a transmutação, a conversão, a síntese, seja qual for a denominação, os motivos executados através de análise qualitativa decoram e melhoraram a sua qualidade, mas também podem desviar a atenção do pano básico que dá a peça a sua força e forma, habilidade, conhecimento, experiência, criatividade, diligência. Não há processos abstratos de análise. Não importa os quão eloquentemente nomeados e finalmente descritos, podem substituir a habilidade, o conhecimento, a experiência, a criatividade, a diligência e o trabalho do analista qualitativo. O desafio da análise qualitativa está em dar sentido a enormes quantidades de dados. Trata-se de reduzir o volume de informação bruta, peneirando e dando significados, identificando padrões significativos e construindo uma estrutura para comunicar a essência do que os dados revelam (Patton, 2002).

Não há fórmulas para determinar a significância. Não existem formas de replicar perfeitamente os processos de pensamento analítico do pesquisador. Nenhum teste simples pode ser aplicado para a confiabilidade e a validade. Em suma, não existem regras absolutas exceto talvez isto: faça o seu melhor com o seu intelecto para representar de forma justa os dados e comunicar o que os dados revelam, dada a finalidade do estudo (Patton, 2002).

\subsubsection{Relatório da Pesquisa}

A última etapa do processo de pesquisa é a redação do relatório (Gil, 2012). Os relatórios de estudos qualitativos seguem formatos variados (Glaser \& Strauss, 1966; Klenow, 1981), muitos dos quais podem aparecer altamente ortodoxos e inaceitáveis para o leitor que está acostumado a ler os resultados de estudos experimentais (Knafl \& Howard, 1984). 
O procedimento básico no relato dos resultados de um estudo qualitativo é desenvolver descrições e temas que comuniquem perspectivas múltiplas dos participantes e descrições detalhadas do local ou dos indivíduos. Utilizando-se uma estratégia de investigação qualitativa, esses resultados podem também proporcionar uma narrativa cronológica da vida de um indivíduo (pesquisa narrativa), uma descrição detalhada de suas experiências (fenomenologia), uma teoria gerada dos dados (teoria fundamentada), um retrato detalhado de um grupo que compartilha uma cultura (etnografia) ou uma análise profunda de um ou mais casos (estudo de caso) (Creswell, 2010).

O pesquisador precisa saber as características do público a que se destina o relatório. Qualquer que seja o público a que é dirigido o relatório, alguns aspectos devem ser considerados pelo pesquisador, ou seja, certas normas referentes à estrutura do texto, ao seu estilo e à sua apresentação gráfica (Gil, 2012).

Schrader (1974, p. 257) apresenta os elementos essenciais do relatório final de pesquisa: “O relatório inicia com a formulação do problema, expõe dados da literatura existente sobre o tema, explicita a posição teórico-científica". O relatório deve conter informações suficientes para esclarecer acerca da natureza do problema pesquisado e dos resultados. Deve, ainda, indicar os procedimentos adotados para coleta e análise dos dados bem como informar acerca das fontes pesquisadas (Gil, 2012). Em resumo o relatório de pesquisa deve apresentar: (i) o problema, (ii) a metodologia, (iii) os resultados e (iv) as conclusões e sugestões.

\section{REFERÊNCIAS}

Assis, J. d. (1993). Kuhn e as ciências sociais. Estudos Avançados, 7(19), 133-164. doi:10.1590/S0103-40141993000300004

Atweh, B., Kemmis, S., \& Weeks, P. (1998). Action Research in Practice: Partnership for Social Justice in Education. New York: Routledge.

Bansal, P., \& Corley, K. (2017). Publishing in AMJ-Part 7: What's Different about Qualitative Research? Academy of Management Journal, 55(3), 509-513. doi:10.5465/amj.2012.4003

Bansal, P., Smith, W. K., \& Vaara, E. (2018). Research, New Ways of Seeing through Qualitative. Academy of Management Journal, 61(4), 1189-1195. doi:10.5465/amj.2018.4004

Bauer, H. H. (1994). Scientific literacy and the myth of the scientific method. Illinois: University of Illinois Press.

Bento, A. M., \& Ferreira, M. R. (2013). A prática da pesquisa em ciência social: uma estratégia de decisão e ação. Revista de Administração Pública, 17(4), 4-39.

Berger, P. L., \& Luckmann, T. (1967). The social construction of reality. Penguin Books .

Berkeley, G. (1996). Principles of Human Knowledge and Three Dialogues. Oxford University Press.

Bertero, C. O. (2013). Área Qualitativa em Ciências Sociais e Estudos Organizacionais. Em A. R. Takahashi, Pesquisa Qualitativa em Administração: Fundamentos, Métodos e Usos no Brasil (pp. 7-22). São Paulo: Atlas.

Beuren, I. M., Longaray, A. A., Raupp, F. M., \& Batista, M. A. (2003). Como Elaborar Trabalhos Monográficos em Contabilidade. Teoria e Prática (3 ed.). São Paulo: Atlas.

Bogdan, R. C., \& Biklen, S. K. (1998). Qualitative research in education. An introduction to theory and methods (3 ed.). Needham Heights. 
Boni, V., \& Quaresma, S. J. (2005). Aprendendo a entrevistar: como fazer entrevistas em Ciências Sociais. Em Tese, 2(1), 68-80.

Borg, W. (1974). Investigación educacional: una introducción. Em J. C. Hayman, Investigación y educación. Paidós, Buenos Aires.

Brannen, J. (1992). Mixing Methods: qualitative and quantitative research. Aldershot: Avebury.

Bryman, A. (2012). Social research methods (4 ed.). New York: Oxford.

Bulgacov, Y. L. (2013). Debate Epistemológico, Ontológico e Metodológico. Em A. R. Takahashi, Pesquisa Qualitativa em Administração: Fundamentos, Métodos e Usos no Brasil (pp. 7-22). São Paulo: Atlas.

Burrell, G., \& Morgan, G. (1979). Sociological paradigms and organisational analysis. London: Heinemann.

Charmaz, K. (2006). Constructing grounded theory: A practical guide through qualitative analysis. London: Pine Forge Press.

Cheek, J. (2004). At the Margins? Discourse Analysis and Qualitative Research. Qualitative Health Research, 14(8), 1140-1150. doi:10.1177/1049732304266820

Chizzotti, A. (2003). A pesquisa qualitativa em ciências humanas e sociais: evolução e desafios. Revista Portuguesa de Educação, 16(2), 221-236.

Clandinin, D. J., \& Connelly, F. M. (2000). Narrative inquiry: Experience and story in qualitative research. San Francisco: Jossey-Bass.

Corbin, J., \& Strauss, A. (1990). Basics of qualitative research: Grounded theory procedures and techniques (1 ed.). Newbury Park, CA: Sage.

Corbin, J., \& Strauss, A. (1998). Basics of qualitative research: Grounded theory procedures and techniques (2 ed.). Thousand Oaks, CA: Sage.

Cornforth, M. C. (1968). Materialism and the dialectical method. New York: International Publishers.

Cresswell, J. W. (2003). Research design: Qualitative, quantitative, and mixed methods approaches (2 ed.). Thousand Oaks: Sage.

Creswell, J. W. (2007). Qualitative inquiry \& research design: Choosing among five approaches ( 2 ed.). Thousand Oaks, London: Sage.

Creswell, J. W. (2008). Educational research: Planning, conducting, and evaluating quantitative and qualitative research (3 ed.). Merrill, NJ: Upper Saddle River.

Creswell, J. W. (2010). Projeto de Pesquisa: métodos qualitativos, quantitativos e misto (3 ed.). Porto Alegre: Artmed.

Creswell, J. W. (2013). Research design: Qualitative, quantitative, and mixed methods approaches (4 ed.). London: Sage Publications.

Creswell, J. W., \& Clark, V. L. (2007). Designing and conducting mixed methods research. Thousand Oaks, CA: Sage publications.

D’Azevedo, M. A. (1994). Visão contingencial das relações públicas: paradigma funcionalista. Revista Biblioteconomia \& Comunicação, 6(1), 67-79.

Denzin, N. K., \& Lincoln, Y. S. (2005). Introduction: the discipline and practice of qualitative research. Em Norman Kent Denzin, \& Y. S. Lincoln, The Sage handbook of qualitative research (3 ed., pp. 1-32). Thousand Oaks: Sage.

Denzin, N. K., \& Lincoln, Y. S. (2006). O planejamento da pesquisa qualitativa: teorias $e$ abordagens (2 ed.). Porto Alegre: Artmed.

Denzin, N. K., \& Lincoln, Y. S. (2011). DENZIN, Norman K.; LINCOLN, Yvonna S. (Ed.). The SAGE handbook of qualitative research. London: Sage.

Fraenkel, J. R., Wallen, N. E., \& Hyun, H. H. (2019). How to design and evaluate research in education (10 ed.). New York: McGraw-Hill. 
Franzolin, J. (2013). Pesquisa-Ação. Em A. R. Takahashi, Pesquisa Qualitativa em Administração: Fundamentos, Métodos e Usos no Brasil (pp. 223-258). São Paulo: Atlas.

Gall, M. D., Borg, W. R., \& Gall, J. P. (2003). Educational research: An introduction (7 ed.). New York: Allyn \& Bacon.

Garfinkel, H. (2003). Ethnomethodology. Em M. Slattery, Key Ideas in Sociology (pp. 104108). Cheltenham: Nelson Thornes.

Gil, A. C. (2012). Métodos e Técnicas de Pesquisa Social (6 ed.). São Paulo: Atlas.

Gill, P., Stewart, K., Treasure, E., \& Chadwick, B. (2008). Methods of data collection in qualitative research: interviews and focus groups. British dental journal, 204(6), 291295. doi:10.1038/bdj.2008.192

Glaser, B. G., \& Strauss, A. L. (1966). The purpose and credibility of qualitative research. Nursing research, 15(1), 56-61.

Godoy, A. S. (2013). Fundamentos da Pesquisa Qualitativa. Em A. R. Takahashi, Pesquisa Qualitativa em Administração: Fundamentos, Métodos e Usos no Brasil (pp. 35-49). São Paulo: Atlas.

Godoy, A. S. (1995). Introdução à pesquisa qualitativa e suas possibilidades. Revista de administração de empresas, 35(2), 57-63.

Grinnell, R. M. (1997). Social work research and evaluation: Quantitative and qualitative approaches. 4.ed. Itasca, IL: FE. Peacock. 1997. (4 ed.). Itasca: FE. Peacock.

Hall, R. A. (1983). The revolution in Science 1500-1750. Longman.

Hazard, P. (1994). La crise de la conscience européenne 1680-1715. Paris: Le Livre de Poche.

Hegel, G. F. (1931). The Phenomenology of Mind . (1841 edition, trans. JB Baillie).

Hegenberg, L. (2012). Método. Em L. Hegenberg, A. H. Júnior, \& F. E. Hegenberg, Métodos de Pesquisa-de Sócrates a Marx e Popper. São Paulo: Atlas.

Hug, S. (2013). Qualitative Comparative Analysis: How inductive use and measurement error lead to problematic inference. Political Analysis, 21(2), 252-265. doi:10.1093/pan/mps061

Hughes, C. (2003). Disseminating Qualitative Research in Educational Settings. Glasgow: McGraw-Hill International.

Johnson, R. B., \& Onwuegbuzie, A. J. (2004). Mixed methods research: A research paradigm whose time has come. Educational researcher, 33(7), 14-26. doi:10.3102/0013189X033007014

Kemmis, S., \& Wilkinson, M. (1998). Participatory action research and the study of practice. Em B. Atweh, S. Kemmis, \& P. Weeks, Action Research in Practice: partnerships for social justice in education. London: Routledge.

King, G., Keohane, R. O., \& Verba, S. (1994). Designing social inquiry: Scientific inference in qualitative research. New Jersey: Princeton University Press.

Kirk, J., \& Miller, M. L. (1986). Reliability and Validity in Qualitative Research. California: Sage.

Klenow, D. J. (1981). Qualitative methodology: A neglected resource in nursing research. Research in Nursing \& Health, 4(3), 281-282. doi:10.1002/nur.4770040302

Knafl, K. A., \& Howard, M. J. (1984). Interpreting and reporting qualitative research. Research in nursing \& health, 7(1), 17-24. doi:10.1002/nur.4770070105

Kockelmans, J. J. (1994). Edmund Husserl's phenomenology. Purdue University Press.

Koyré, A. (1973). Du monde clos à l'univers infini. Paris: Colectikon TEL, Gallimard.

Kuhn, T. S. (1996). The structure of scientific revolutions. Londres: University of Chicago press.

Lakatos, E. M., \& Marconi, M. d. (2011). Metodologia científica (6 ed.). São Paulo: Atlas. 
Lefebvre, H. (2009). Dialectical materialism. Minneapolis: U of Minnesota Press.

Locke, L. F., Spirduso, W. W., \& Silverman, S. J. (2013). Proposals that work: A guide for planning dissertations and grant proposals. London: Sage Publications.

Ludke, M., \& André, M. E. (1986). Pesquisa em educação: abordagens qualitativas. Editora Pedagógica e Universitária.

Lyberg, L., \& Kasprzyk, D. (2004). Data collection methods and measurement error: an overview. Em P. P. Biemer, R. M. Groves, L. E. Lyberg, N. A. Mathiowetz, \& S. Sudman, Measurement errors in surveys (pp. 235-257). New York: Wiley.

Marcuschi, L. A. (2002). Do código para a cognição: o processo referencial como atividade criativa. Veredas: revista de estudos lingüísticos, 6(1), 43-62.

Marshall, C., \& Rossman, G. B. (2006). Designing Qualitative Research (4 ed.). Thousand Oaks, CA: Sage.

May, T. (2011). Social Research: Issues, Methods and Research (4 ed.). New York: McGrawHill International.

McGinn, C. (1980). Philosophical materialism. Synthese, 44(2), 173-206.

Mendonça, A. T. (2013). Grounded Theory. Em A. R. Takahashi, Pesquisa Qualitativa em Administração: Fundamentos, Métodos e Usos no Brasil (pp. 189-221). São Paulo: Atlas.

Merriam, S. B. (1998). Qualitative Research and Case Study Applications in Education. Revised and Expanded from "Case Study Research in Education". San Francisco: Jossey-Bass Publishers.

Miles, M. B., Huberman, A. M., \& Saldaña, J. (2013). Qualitative data analysis: A methods sourcebook. Thousand Oaks, CA: Sage Publications.

Miller, W. L., \& Crabtree, B. F. (1992). Primary care research: A multimethod typology and qualitative road map. Em B. F. Crabtree, \& W. L. Miller, Research methods for primary care (pp. 3-28). Sage Publications.

Morgan, G., \& Smircich, L. (1980). The case for qualitative research. Academy of management review, 5(4), 491-500. doi:10.5465/amr.1980.4288947

Moustakas, C. (1994). Phenomenological research methods. Thousand Oaks, CA: Sage.

Neergaard, H., \& Ulhoi, J. P. (2007). Handbook of qualitative research methods in entrepreneurship. Edward Elgar Publishing.

Neves, J. L. (1996). Pesquisa qualitativa: características, usos e possibilidades. Caderno de pesquisas em administração, 1(3), 1-5.

Oilman, B. (1976). On Teaching Marxism. Insurgent Sociologist, 6(4), 37-50. doi:10.1177/089692057600600406

Patton, M. Q. (2002). Qualitative Research \& Evaluation Methods (3 ed.). London: Sage.

Paulilo, M. A. (1999). A pesquisa qualitativa e a história de vida. Serviço social em revista, 2(1), 135-145.

Philips, M. (2003). Philosophy \& the Paranormal: What is Materialism? Philosophy Now.

Ramsden, P., \& Moses, I. (1992). Associations between research and teaching in Australian higher education. Higher Education, 23(3), 273-295. doi:10.1007/BF00145017

Richardson, R. J. (2010). Pesquisa social: métodos e técnicas (3 ed.). São Paulo: Atlas.

Roark, D. M. (1982). Introduction To Philosophy. Dalmor Pub.

Sampieri, R. H., Callado, C. F., \& Lucio, M. d. (2013). Metodologia de Pesquisa (5 ed.). Porto Alegre: Penso.

Sanders, P. (1982). Phenomenology: a new way of viewing organizational research. Academy of management review, 7(3), 353-360. doi:10.5465/amr.1982.4285315

Schrader, A. (1974). Introdução à pesquisa social empírica. Porto Alegre: Globo.

Shanteau, J. (1972). Descriptive versus normative models of sequential inference judgment. Journal of Experimental Psychology, 93(1), 63-68. doi:10.1037/h0032509 
Silva, M. L., \& Emmendoerfer, M. L. (2014). Resenha Bibliográfica - Pesquisa Qualitativa em Administração: Fundamentos, Métodos e Usos no Brasil. Organizações em contexto, 10(20), 453-458. doi:10.15603/1982-8756/roc.v10n20p453-458

Silverman, D. (2017). Doing qualitative research (5 ed.). London: Sage Publications.

Smithson, I. (1975). Structuralism as a Method of Literary Criticism. College English, 37(2), 145-159. doi: $10.2307 / 375060$

Stake, R. E. (1995). The art of case study research. Newbury Park, CA: Sage Publications.

Tesch, R. (1990). Qualitative research: Analysis types and software tools. New York: Falmer.

Thomas, G. (2011). A typology for the case study in social science following a review of definition, discourse, and structure. Qualitative Inquiry, 17(6), 511-521.

Thomas, J. R., Nelson, J. K., \& Silverman, S. J. (2015). Research methods in physical activity (7 ed.). Champaign: Human Kinetics.

Thorpe, R., \& Holt, R. (2007). The Sage dictionary of qualitative management research. London: Sage.

Triviños, A. N. (2008). Introdução à pesquisa em ciências sociais: a pesquisa em educação (1 ed.). São Paulo: Atlas.

Vaus, D. d. (2014). Surveys in social research (6 ed.). London: Routledge.

Vera, A. A. (1979). Metodologia da pesquisa científica (5 ed.). Porto Alegre: Globo.

Voloshinov, V. N. (1973). Marxism and the Philosophy of Language. New York: Seminar Press.

Walle, A. H. (2015). Qualitative Research: A Practical Overview. Newcastle upon Tyne, England : Cambridge Scholars Publishing.

Wolcott, H. F. (1999). Ethnography: A way of seeing. Walnut Creek, CA: AltaMira Press.

Wolcott, H. F. (2001). Writing up qualitative research. Thousand Oaks, CA: Sage.

Yin, R. K. (2009). Case study research: Design and methods. Sage.

Yin, R. K. (2010). Qualitative research from start to finish. Guilford Press. 